Aus der Abteilung Neurologie

(Prof. Dr. med. M. Bähr)

im Zentrum Neurologische Medizin

der Medizinischen Fakultät der Universität Göttingen

\title{
Untersuchung der oligodendroglialen Membranstruktur in einem Zellkulturmodell
}

\author{
INAUGURAL-DISSERTATION \\ zur Erlangung des Doktorgrades \\ der Medizinischen Fakultät \\ der Georg-August-Universität zu Göttingen
}

\author{
vorgelegt von \\ Dirk Fitzner \\ aus \\ Ansbach
}

Göttingen 2012 
Dekan:

I. Berichterstatterin:

II. Berichterstatter/in:

Tag der mündlichen Prüfung
Prof. Dr. med. M. Schön

Prof. Dr. med. M. Simons

Prof. Dr. S. Rizzoli 


\section{Inhaltsverzeichnis}

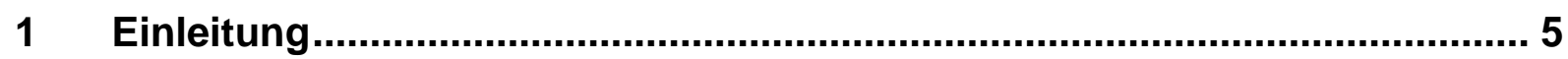

1.1 Organisationsstruktur des Nervensystems …........................................................ 5

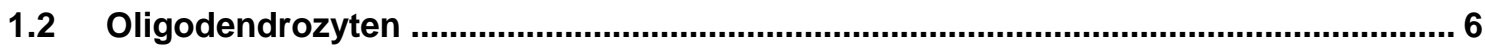

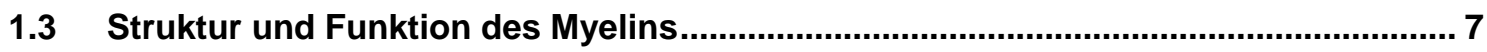

1.4 Struktur und Funktion des basischen Myelinproteins (MBP) …............................... 9

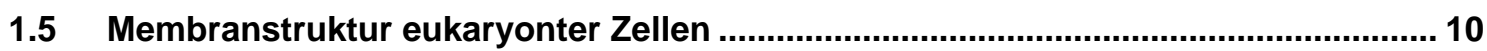

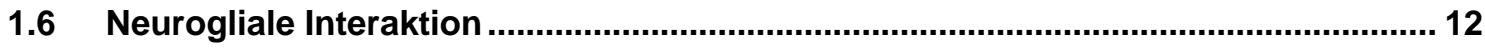

2 Zielsetzung/Fragestellung .................................................................. 14

3 Zusammenfassung der Ergebnisse................................................... 14

3.1 Die Gegenwart von Neuronen in primären Oligodendrozytenkulturen führt zur Umverteilung bestimmter oligodendroglialer Membranbestandteile.

Abbildung 1: Oligodendrogliale Zellen differenzieren unter Kulturbedingungen zu reifen

Oligodendrozyten und beginnen neuronale Zellfortsätze zu myelinisieren.

Abbildung 2: Die Anwesenheit von Neuronen in einer Oligodendrozyten-Kultur führt zu einer

zunehmenden Ko-Lokalisation bestimmter Proteine und Lipide.

3.2 Nach Ko-Kultivierung von Oligodendrozyten mit Neuronen findet sich

eine Anreicherung der Myelinproteine MBP und PLP in spezifischen Membrandomänen.

Abbildung 3: In der neuroglialen Ko-Kultur findet sich eine zunehmende CHAPS-Unlöslichkeit von PLP und MBP.

Abbildung 4: Reduktion der GalC-Konzentration in der oligodendroglialen Membran führt zu einer Abnahme der MBP-Menge in der CHAPS-unlöslichen Fraktion. Der Anteil CHAPSunlöslicher Lipide im Myelin ist größer als in den Zellen einer Oligodendrozyten-Monokultur.

3.3 In Anwesenheit von Neuronen findet sich eine Zunahme des Ordnungsgrades der oligodendroglialen Membran.

Abbildung 5: Die Zellmembran von Oligodendrozyten einer Monokultur weist nur wenige kondensierte Bereiche auf.

Abbildung 6: In Anwesenheit von Neuronen findet sich eine zunehmende Kondensation der oligodendroglialen Membran.....

3.4 Neurone induzieren die Bildung von mobilen Galactosylceramid-

Clustern in der oligodendroglialen Membran.

Abbildung 7: Neurone induzieren die Bildung mobiler GalC-Cluster in der oligodendroglialen 
Abbildung 8: In Anwesenheit von Neuronen steigt die Größe der in der oligodendroglialen

Membran nachweisbaren GalC-Cluster.

3.5 Die Umstrukturierung der oligodendroglialen Membran nach Ko-

Kultivierung mit Neuronen ist MBP-abhängig.

Abbildung 9: Die Umstrukturierung der oligodendroglialen Membran in MBP-abhängig......

4 Diskussion

5 Literaturverzeichnis. 


\section{Einleitung}

\subsection{Organisationsstruktur des Nervensystems}

Das Nervensystem von Vertebraten lässt sich in einen peripheren und einen zentralen Anteil unterteilen, wobei das periphere Nervensystem (PNS) periphere Nerven und Ganglien und das zentrale Nervensystem (ZNS) Gehirn und Rückenmark umfasst. Die zwei Bereiche unterscheiden sich nicht nur hinsichtlich ihrer Funktionen, sondern auch bezüglich ihrer zellulären und molekularen Zusammensetzung (Kandel ER et al. 2000).

Hierbei besteht das periphere Nervensystem aus Nervenzellen, die den ventralen und dorsalen Spinalwurzeln sowie den Spinalganglien entspringen und Verbindungen zwischen dem ZNS und der Peripherie des Körpers herstellen. Neben neuronalen Strukturen finden sich im PNS Gliazellen, namentlich Makrophagen und Schwannzellen. Makrophagen beteiligen sich z.B. als Phagozyten an Reparaturvorgängen nach Schädigung eines peripheren Nervens. Schwannzellen gewährleisten die Myelinisierung peripherer Axone. Zusätzlich existieren nicht myelinisierende Schwannzellen, die dünne, nicht myelinisierte Axone zu sogenannten Remakbündeln zusammenfassen (Griffin JW und Thompson WJ 2008; Pereira JA et al. 2012).

In den neuronalen Netzwerken des ZNS werden die aus der Peripherie kommenden Impulse verarbeitet und Verhalten z.B. in Form motorischer Handlungen generiert. Neben den hierfür verantwortlichen unterschiedlich differenzierten Populationen von Neuronen besteht das Gewebe des ZNS jedoch zu einem größeren Teil aus Gliazellen. Diese umfassen Astrozyten, Mikroglia und Oligodendrozyten.

Astrozyten erfüllen neben Aufgaben der strukturellen Organisation auch Funktionen der Homöostase und der Trophik (Kacem K et al. 1998; Barres BA 2008; Nedergaard M und Verkhratsky A 2012). Mikroglia sind monozytäre Zellen mesodermalen Ursprungs, die insbesondere als professionelle gewebsständige Phagozyten fungieren und hierbei eine wichtige Rolle in der lokalen Immunabwehr spielen (Kettenmann $\mathrm{H}$ et al. 2011). 


\subsection{Oligodendrozyten}

Oligodendrozyten sind die myelinisierenden Zellen des ZNS. Sie entstehen aus Vorläuferzellen, die vor allem während der Embryonalentwicklung im Neuroepithel des Neuralrohrs entstehen. Diese pluripotenten Vorläuferzellen (engl. „oligodenrocyte precursor cells" - OPC) reifen unter dem Einfluss lokaler Differenzierungsfaktoren zu proliferierenden bipolaren Zellen heran, die in das Marklager mit der entstehenden weißen Substanz migrieren (Kessaris $\mathrm{N}$ et al. 2006). Erst hier differenzieren die Zellen zu reifen Oligodendrozyten, die die typischen Myelinproteine wie z.B. das basische Myelinprotein (engl. "myelin basic protein" - MBP), das Proteolipid-Protein (PLP) oder das Myelin-assoziierte Glycoprotein (MAG) exprimieren und eine typische Zellmorphologie aufweisen (Baumann N und Pham-Dinh D 2001).

Dieser Differenzierungsprozess wird in großem Maße durch Umgebungsfaktoren wie z.B. den Fibroblasten-Wachstumsfaktor (engl. "fibroblast growth factor" - FGF), den Insulinähnlichen Wachstumsfaktor 1 (engl. „insulin-like growth factor 1“ - IGF-1) oder auch neurotrophe Faktoren wie z.B. den "ciliary neurotrophic factor" (CNTF) und Hormone wie das Schilddrüsenhormon T3 beeinflusst und gesteuert. Das Vorhandensein dieser Signale in den entsprechenden Entwicklungsstadien führt zur Induktion von Transkriptionsfaktoren wie z.B. Olig1/2, Sox10 und Nkx2.2/2.6 und schließlich zur Expression der obengenannten Proteine in reifen Oligodendrozyten (Baumann N und Pham-Dinh D 2001; Colognato H und ffrench-Constant C 2004). Erst in Beisein neuronaler Faktoren werden die letzten Schritte der Differenzierung eingeleitet und schließlich die eigentliche Myelinisierung initiiert (Sherman DL und Brophy PJ 2005). Hierzu muss neben der koordinierten Expression der Myelinproteine auch die Bildung großer Mengen an Lipiden erfolgen. Dies wird nötig, da die Myelinscheide aus großflächigen Ausläufern der oligodendroglialen Zellmembran besteht, die in mehreren engen Lagen das Axon umhüllen und somit große Mengen Membranmaterial enthalten (Aggarwal S et al. 2011).

Im Gegensatz zu Schwannzellen, die in der Peripherie jeweils nur ein Axon pro Zelle myelinisieren, entsenden Oligodendrozyten mehrere Prozessus, die Kontakt mit Axonen aufnehmen und diese mit Myelin umhüllen. Hierbei kann ein einzelner Oligodenrozyt bis zu 40 Axone myelinisieren (Baumann N und Pham-Dinh D 2001).

Obwohl diese Prozesse während der Entwicklung des ZNS durch ein komplexes Zusammenspiel verschiedener Faktoren reguliert werden, um so eine zeitgerechte 
Abfolge der Differenzierungsstadien mit dem Ziel einer regelrechten Myelinisierung zu gewährleisten, lassen sich einzelne Entwicklungsstadien oligodendroglialer Zellen auch in vitro in Zellkulturmodellen nachstellen und untersuchen. Hierbei scheinen gliale Zellen, die in primären Zellkulturen, welche aus embryonalen Mäusehirnen präpariert und in entsprechend substituierten Zellkulturmedien kultiviert werden, nach einem intrinsischen Programm nur eine bestimmte Anzahl von Proliferationszyklen zu durchlaufen, bevor sie sich schließlich weiter differenzieren. Zum Ende dieser Differenzierung finden sich in einer solchen Oligodendrozyten-angereicherten Kultur Zellen mit großen, flächigen Membranausläufern, die zahlreiche Marker reifer Oligodendrozyten wie z.B. MBP, PLP und MAG tragen. Werden diese Zellen unter Kulturbedingungen mit Neuronen zusammengeführt, beginnen sie, Axone in einem der Myelinisierung ähnlichen Prozess spiralförmig zu umhüllen (Lubetzki $C$ et al. 1993; Trajkovic K et al. 2006).

\subsection{Struktur und Funktion des Myelins}

Die Bildung von Myelin ist die zentrale Aufgabe von Oligodendrozyten. Während des Myelinisierungsprozesses umhüllen Oligodendrozyten Axone mit spiralförmig angeordneten Membranlagen. Hieraus ergibt sich die aus zahlreichen stark kompaktierten Membranschichten bestehende Myelinscheide, wobei während des Myelinisierungsprozesses ein großer Teil des zwischen den Membranstapeln befindlichen Zytoplasmas abtransportiert wird (Hartline DK 2008).

Die Myelinscheide weist nicht nur ihren Querschnitt betreffend eine einheitliche periodische Struktur mit regelmäßiger Anordnung der oligodendroglialen Membranlagen auf, sondern zeigt auch im longitudinalen Schnitt einen regelhaften Aufbau. Hierbei wechseln sich entlang eines Axons myelinisierte Segmente mit

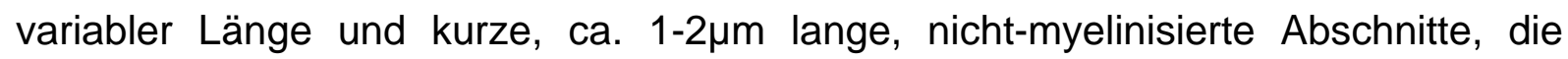
sogenannten Ranvierschen Schnürringe, ab. Im Bereich dieser Schnürringe findet sich eine hohe Dichte von spannungsgesteuerten Natrium- und Kaliumkanälen. Diese Anordnung ist (neben den isolierenden Eigenschaften der Myelinscheide) Voraussetzung für die an myelinisierten Axonen stattindende saltatorische Erregungsleitung, welche zu einer deutlichen Steigerung der Geschwindigkeit der Reizweiterleitung führt (Baumann N und Pham-Dinh D 2001).

Die Komposition der Myelinmembran unterscheidet sich in bestechender Weise von anderen Zellmembranen und macht zugleich den größten Anteil der Membranmasse 
des ZNS aus. Myelin besteht zu ca. 70-80\% seines Trockengewichtes aus Lipiden. Obwohl hierbei keine Myelin-spezifischen Lipide existieren, findet sich eine im Vergleich zu anderen Membranen ungewöhnlich hohe Anreicherung von Glycolipiden insbesondere von Glycosphingolipiden, im Speziellen von Galactosylceramid (GalC) und Sulfogalactosylceramid (sGalC). Zusätzlich sind aus der Gruppe der Phospholipide Phosphatidylethanolamine und hierbei vor allem Plasmalogene angereichert (Deber CM und Reynolds SJ 1991). Tabelle 1 gibt einen Überblick über die Konzentrationen einzelner Lipidklassen bzw. Lipide in der Myelinmembran im Vergleich zu den Verhältnissen in der Membran einer Leberzelle (Chrast R et al. 2011).

\begin{tabular}{|l|c|c|}
\hline Lipidklasse/Lipid & $\begin{array}{l}\text { prozentualer Anteil des } \\
\text { Lipids in der Myelinmembran }\end{array}$ & $\begin{array}{l}\text { prozentualer Anteil des } \\
\text { Lipids in der Membran einer } \\
\text { Leberzelle }\end{array}$ \\
\hline$\underline{\text { Cholesterol }}$ & 26 & 17 \\
\hline Phospholipide & 16 & 7 \\
\hline Phosphatidylethanolamin & 6 & 24 \\
\hline Phosphatidylserin & 12 & 4 \\
\hline Phosphatidylcholin & 1 & 20 \\
\hline Phosphatidylinositol & 3 & 7 \\
\hline Sphingomyelin & 31 & 17 \\
\hline Glycolipide & 5 & \\
\hline Andere Lipide & & \\
\hline
\end{tabular}

Des Weiteren enthält diese hochspezialisierte Membran nicht nur einen vergleichsweise niedrigen Proteingehalt, sondern zusätzlich eine eingeschränkte Vielfalt von Proteinen. Ein großer Anteil der gesamten Proteinmasse der Membran besteht aus den beiden Myelinproteinen PLP und MBP. Darüber hinaus finden sich, ebenfalls als Myelin-spezifische Proteine, MAG, das Myelin Oligodenrozyten Glycoprotein (MOG) und die cyclische Nukleosid-Phosphodiesterase (CNP). Die 
Anzahl der übrigen Myelinproteine ist vergleichsweise gering (Jahn $O$ et al. 2009). Außerdem finden sich viele der genannten Proteine innerhalb abgrenzbarer Domänen des Oligodendrozyten (Aggarwal S et al. 2011) oder Z.B. in definierten Bereichen in Bezug zum myelinisierten Axon (Chang KJ et al. 2010).

Ergänzend ist zu erwähnen, dass die von Oligodendrozyten gebildete Myelinscheide nicht nur die saltatorische Erregunsweiterleitung ermöglicht, sondern die oligodendrogliale Membran zusätzlich Einfluss z.B. auf axonale Transportprozesse und die Trophik des Neurons hat. Diese Interaktion wird z.B. an den Folgen krankhafter demyelinisierender Prozesse wie zum Beispiel der Multiplen Sklerose ersichtlich, die häufig auch zu einer Störung der neuronalen Integrität führen (Nave KA und Trapp BD 2008).

\subsection{Struktur und Funktion des basischen Myelinproteins (MBP)}

Das Protein MBP existiert in verschiedenen Isoformen, die sich aus SplicingVarianten eines mRNA-Transkriptes des sogenannten GOLLI-Genkomplexes (engl. "gene of oligodendrocyte lineage") ergeben. Die beim adulten Menschen vorwiegend exprimierte Variante hat ein Molekulargewicht von 18,5 kDa (Harauz G et al. 2009). Das Protein spielt eine wesentliche Rolle im Myelinisierungsprozess, was unter anderem durch den Phänotyp der Knock-out-Maus Shiverer belegt wird. Bei dieser Mauslinie findet sich eine langstreckige Deletion der für MBP codierenden Genabschnitte und somit ein Ausfall der Expression des Proteins (Roach A et al. 1985). Dies führt zu einer deutlichen Hypomyelinisierung und strukturellen Veränderungen des verbleibenden Myelins sowie zu einem ausgeprägten Tremor und Krampfanfällen. Die Tiere zeigen die ersten Symptome nach ca. 14 Tagen und versterben in der Regel innerhalb von 50 bis 100 Tagen (Chernoff GF 1981).

MBP ist ein zytosolisches Protein, das durch seine zahlreichen basischen Aminosäuren eine positive Ladung besitzt. Es beinhaltet zahlreiche Regionen, die durch posttranslationale Modifikationen wie z.B. Methylierungen oder Phosphorylierungen verändert werden können, wodurch auch die Ladungseigenschaften des Proteins beeinflusst werden (Harauz $G$ et al. 2004). MBP hat aufgrund seiner positiven Ladung eine starke Affinität zu den anionischen Lipiden des inneren/zytosolischen Leaflets der Bilayer-Zellmembran (Hu Y et al. 2004). Dies führt dazu, dass MBP auf immun-elektromikroskopischen Aufnahmen der Myelinscheide zwischen den beiden, dem Zytosol zugewandten Membranflächen der 
kompaktierten Membranstapel zu finden ist. Infolge der engen Apposition der beiden zytosolischen Leaflets entsteht eine auf elekronenmikroskopischen Aufnahmen zu erkennende Struktur innerhalb der Myelinscheide, die sogenannte "major dense Line“. Mehrere Studien konnten zeigen, dass MBP sowohl elektrostatische als auch hydrophobe Interaktionen mit der zytoplasmatischen Seite der Zellmembran eingeht und so eine enge Apposition benachbarter Membranflächen vermitteln kann (Boggs J 2006).

\subsection{Membranstruktur eukaryonter Zellen}

Eukaryonte Zellen sind von einer Zellmembran umgeben, die die Ausdehnung der Zelle definiert und zugleich das Milieu im Zellinneren auch bei schwankenden äußeren Bedingungen konstant hält. Zellmembranen bestehen als sogenannte „Bilayer" aus einer Lipiddoppelschicht amphipathischer Lipide, die einen hydrophilen Kopfteil und einen hydrophoben Schwanzteil besitzen. Hierbei lagern sich zwei "Monolayer" von Lipiden entlang ihrer hydrophoben Anteile aneinander an und formen so eine „Bilayer"-Membran. Eine solche Zellmembran bildet also eine hydrophile Fläche, die dem Zytoplasma und eine, die dem Extrazellulärraum zugewandt ist. Man unterscheidet hierbei, den beiden Monolayern entsprechend, ein sogenanntes inneres, zytoplasmatisches Leaflet und ein äußeres Leaflet. Diese fluide, dynamische Membran ist hinsichtlich ihrer Zusammensetzung hochvariabel und kann den entsprechenden Zellfunktionen angepasst werden. Dies geschieht zum einen durch Variation der Lipidkomposition und zum anderen durch Anlagerung beziehungsweise Einbettung von Proteinen (Alberts B et al. 2002).

In biologischen Membranen findet sich eine große Anzahl verschiedener Lipide, wobei in eukaryonten Zellen vor allem Phosphoglyceride, Sphingolipide und Cholesterol nachweisbar sind. Hierbei ist die Zellmembran keine homogene Lipidschicht. Ihre Lipidkomposition kann in Abhängigkeit der gewünschten Funktion nicht nur zwischen unterschiedlichen Zelltypen, sondern auch in verschiedenen Membranbereichen einer Zelle große Unterschiede aufweisen. Dies führt dazu, dass sich innerhalb einer Zellmembran Membrandomänen definieren lassen, die aufgrund ihrer Lipidzusammensetzung häufig auch eine Assoziation mit spezifischen Proteinen aufweisen (Simons K und Sampaio JL 2011).

Zellmembranen sind unter physiologischen Bedingungen fluide, was bedeutet, dass sowohl einzelne Lipidmoleküle als auch komplexere Membrandomänen innerhalb 
des zweidimensionalen Lipid-Bilayers diffundieren können. Hierbei können Diffusionskoeffizienten die Geschwindigkeit der lateralen Diffusion innerhalb einer Membran beschreiben. Die Fluidität einer Membran ist in großem Maße durch ihre Lipidzusammensetzung bestimmt. Umso fluider eine Membran ist, desto später tritt bei sinkender Temperatur der Übergang von einem flüssig-kristallinen in einen gelförmigen oder auch als rigide-kristallinen bezeichneten Zustand ein. Darüberhinaus werden Membranen oder Membrandomänen auch als geordnet oder ungeordnet beschrieben. Membranen erhalten durch eine Anreicherung gesättigter oder/und langer Fettsäuren, wie z.B. Sphingomyelin, eine höhere Ordnung. Geordnete Membranabschnitte verhalten sich gelartig, haben also eine geringe Fluidität und weisen eine langsamere laterale Diffusion auf. Ungeordnete Membranen entstehen dementsprechend durch Anreicherung ungesättigter oder/und kurzer Fettsäuren, deren hydrophobe Wechselwirkungen untereinander reduziert sind, was zu einem niedrigeren Ordnungsniveau innerhalb eines Bilayers führt. Dies resultiert in einer höheren Fluidität und Geschwindigkeit der lateralen Diffusion. Dieser Membranzustand wird als flüssig-ungeordnet bezeichnet (van Meer G et al. 2008).

In eukaryonten Membranen wurde zusätzlich ein sog. flüssig-geordneter Zustand beschrieben, der durch erhöhte Cholesterol-Konzentrationen innerhalb bestimmter Membranbereiche entsteht. Cholesterol alleine bildet als Molekül keine Bilayer, jedoch kann das Molekül quasi in einen bestehenden Bilayer interkalieren und dessen Eigenschaften verändern. Cholesterol lagert sich aufgrund seiner molekularen Eigenschaften hierbei bevorzugt in Sphingolipid-reiche Membranbereiche ein. Diese Einlagerung führt einerseits zu einem höheren Ordnungsgrad der Membran, anderseits bleibt jedoch die Fluidität und somit die laterale Mobilität der Lipide innerhalb des flüssig-geordneten Bereiches erhalten (van Meer $G$ et al. 2008). Aufgrund der dichten Packung von Lipiden werden derartige Membrananteile auch als kondensiert bezeichnet. Membrandomänen mit flüssiggeordneter Struktur kommen in unterschiedlicher Größe vor und sind häufig mit bestimmten Membranproteinen assoziiert. In diesem Zusammenhang hat sich der Begriff Lipid-Raft etabliert (Simons $K$ und Ikonen $E$ 1997). Lipid-Rafts sind dynamische, metastabile, geordnete, mit Cholesterol und Sphingolipiden angereicherte nanoskopische Membrandomänen. Sie enthalten Proteine, deren strukturelle Eigenschaften wie z.B. das Vorhandensein eines GPI-Ankers (Abkürzung 
für Glycosylphosphatidylinositol-Anker), palmitoylierte Transmembrandomänen oder doppelte Acylierungen eine Assoziation mit dem Lipid-Raft begünstigen. Diese LipidProtein-Komplexe zeigen die Tendenz, sich von der sie umgebenden flüssigungeordneten Membranphase zu separieren. Metastabil bedeutet in diesem Zusammenhang, dass sich Lipid-Rafts vermutlich nicht im eigentlichen Sinne wie „Flöße“ innerhalb einer Membran verhalten, sondern in einem dynamischen Prozess in wechselnder Größe und Lokalisation ständig entstehen und wieder zerfallen. Dieser Zustand wird durch Veränderung der Lipid- und Proteinkomposition moduliert. Lipid-Rafts spielen in vielen Zellen verschiedenste Rollen in der Signalübertragung oder bei Transportvorgängen an zellulären Membranen. Ihre Existenz wurde anfänglich durch Untersuchung der Lösungseigenschaften verschiedener Membranbestandteile in zwitterionischen Lösungsmitteln bestätigt. Aufgrund ihrer nanoskopischen und metastabilen Struktur ist die Analyse derartiger Membranbereiche jedoch technisch schwierig (Jacobson K et al. 2007).

Die Verteilung einzelner Lipidmoleküle zwischen den beiden Monolayern ist hingegen nur wenig dynamisch, so dass der Übertritt eines Lipids in ein opponierendes Leaflet nur vergleichsweise selten auftritt. Die biophysikalischen Eigenschaften vieler Lipidmoleküle legen bereits eine präferenzielle Einlagerung in das äußere oder innere Leaflet fest. Zusätzlich ist die Assoziation eines Lipids mit dem äußeren oder inneren Leaflet auch durch seinen Syntheseweg mitbestimmt. Einige Lipide können enzymatisch durch sogenannte Flipasen zwischen den beiden Leaflets transferiert werden. Somit ist die Lipidverteilung der Bilayer-Membran asymmetrisch (van Meer G 2011). So findet sich zum Beispiel das negativ geladene Phosphatidylserin vor allem im zytosolischen Leaflet der Zellmembran, wohingegen Lipide mit einem Cholin-Anteil wie zum Beispiel Phosphatidylcholin und Sphingomyelin im Wesentlichen in der äußeren Membranfläche lokalisiert sind. Am deutlichsten ist diese Asymmetrie im Falle der Glykolipide zu beobachten. Sie finden sich ausschließlich im äußeren Leaflet der Zellmembran (Lingwood CA 2011).

\subsection{Neurogliale Interaktion}

Um einen geregelten Ablauf der Myelinisierung im ZNS zu gewährleisten, bestehen neben den intrinsischen oligodendroglialen Steuermechanismen (Baumann $\mathrm{N}$ und Pham-Dinh D 2001) auch zahlreiche Interaktionen zwischen Oligodendrozyten und Neuronen, die den Prozess in Ort und Zeit regulieren. Dies wird nötig, da die 
Myelinisierung innerhalb eines engen Zeitfensters während der Entwicklung des Nervensystems stattfinden und eine funktionelle Umhüllung der axonalen Strukturen gewährleistet sein muss. Hierbei werden durch neuronale Signale die Proliferation, Differenzierung und das Überleben des Oligodendrozyten reguliert (Nave KA und Trapp BD 2008).

Ein solcher neuronaler Faktor, der sowohl Zellteilung und Reifung als auch Überleben von Oligodendrozyten steuert, ist das dem epidermalen Wachstumsfaktor ähnliche Neuregulin. Im PNS reguliert dieses Molekül unter anderem die Dicke der Myelinschicht (Michailov GV et al. 2004). Im ZNS hingegen beeinflusst Neuregulin durch die Aktivierung von „Erb“-Rezeptoren (engl. "erythroblastosis homologue“) Anzahl und Differenzierungsgrad von Oligodendrozyten (Bozzali M und Wrabetz L 2004; Brinkmann BG et al. 2008). Auch das auf der axonalen Oberfläche lokalisierte Protein Jagged-1 reguliert über den Transmembranrezeptor Notch-1 oligodendrogliale Differenzierung. Sowohl Jagged-1 als auch die neuronalen Faktoren PSA-NCAM (engl. „polysialylated-neural cell adhesion molecule“) und LINGO-1 (engl. „leucine rich repeat and Ig domain containing 1") haben vorwiegend inhibitorischen Einfluss auf die Reifung und Proliferation von Oligodendrozyten (Piaton G et al. 2010; Taveggia C et al. 2010).

All diese Signale beeinflussen somit vor allem die Entwicklung von Oligodendrozyten bis zum Beginn der eigentlichen Myelinisierung, also dem Aufbau einer einheitlich konfigurierten, periodisch spiralförmigen Umhüllung bestimmter Abschnitte des Axons. Über die axonalen Faktoren, die diesen offensichtlich in engen Grenzen festgelegten Prozess steuern, ist bisher nicht viel bekannt. Jedoch ist anzunehmen, dass differenzierte Oligodendrozyten, die zwar auch in Neuronen-freien Zellkulturen große Mengen einer Myelin-ähnlichen Membran mit entsprechender Lipid- und Proteinkomposition synthetisieren (Simons M et al. 2000; Schneider A et al. 2005), in vivo während des Aufbaus der Myelinscheide durch zusätzliche neuronale Faktoren gesteuert werden. Ein solches Signal scheint z.B. die elektrische Aktivität des Axons zu sein (Ishibashi T et al. 2006). Außerdem bestehen Hinweise, dass die Verteilung bestimmter Myelinbestandteile wie z.B. PLP innerhalb der Zellkompartimente des Oligodendrozyten durch neuronale Signale reguliert ist (Trajkovic K et al. 2006). 


\section{Zielsetzung/Fragestellung}

In der vorliegenden Arbeit sollten die Eigenschaften der oligodendroglialen Membran in einem Zellkulturmodell untersucht werden. Oligodendrozyten sind die myelinsierenden Zellen des ZNS. Es stellt sich daher die Frage, ob die Bildung der hochspezialisierten Membrandomäne Myelin mit ihrer einmaligen Lipid- und Proteinkomposition durch Besonderheiten der Struktur der oligodendroglialen Membran wiedergespiegelt wird. Insbesondere sollte untersucht werden, ob die Anwesenheit neuronaler Signale diese Membranstruktur beeinflusst. Hierbei wurde die oligodendrogliale Membran auch als Modelsystem für die Untersuchung der Struktur biologischer Membranen verstanden.

\section{Zusammenfassung der Ergebnisse}

3.1 Die Gegenwart von Neuronen in primären Oligodendrozytenkulturen führt zur Umverteilung bestimmter oligodendroglialer Membranbestandteile.

In der vorliegenden Studie wurden die Eigenschaften der Zellmembran von Oligodendrozyten untersucht. Hierzu wurden primäre Zellkulturen verwendet, in denen murine Oligodendrozyten entweder alleine oder in Anwesenheit von kortikalen Neuronen kultiviert wurden. Die hier verwendeten Oligodendrozyten-Kulturen enthielten nur geringe Anteile von Mikroglia und werden im Folgenden deshalb vereinfachend als Oligodendrozyten-Monokultur bezeichnet. Im Beisein von Neuronen im Kultursystem wird hingegen von einer Ko-Kultur gesprochen.

Es ließ sich beobachten, dass Oligodendrozyten in Abwesenheit von Neuronen bei entsprechender Substitution des Kulturmediums durch Pferdeserum, L-Thyroxin, Trijodthyroxin, Glukose, Glutamin und den Wachstumsfaktoren des B27Supplements nach einer Kulturzeit von ca. 2 Tagen zunächst ein ausgedehntes Netzwerk von Zellfortsätzen bildeten. Nach weiteren zwei bis drei Tagen entwickelten die Zellen großflächige dünne blattartige Membranausläufer und exprimierten typische Proteine reifer Oligodendrozyten wie zum Beispiel MBP. Wurden diesen Oligodendrozyten-Monokulturen bereits zu Beginn der Kulturzeit Neurone hinzugefügt, begannen Oligodendrozyten, ihre Zellfortsätze entlang neuronaler Zellfortsätze auszurichten. Hierbei konnte elektronenmikroskopisch nachgewiesen werden, dass Oligodendrozyten damit begannen, neuronale Zellausläufer zu myelinisieren. 

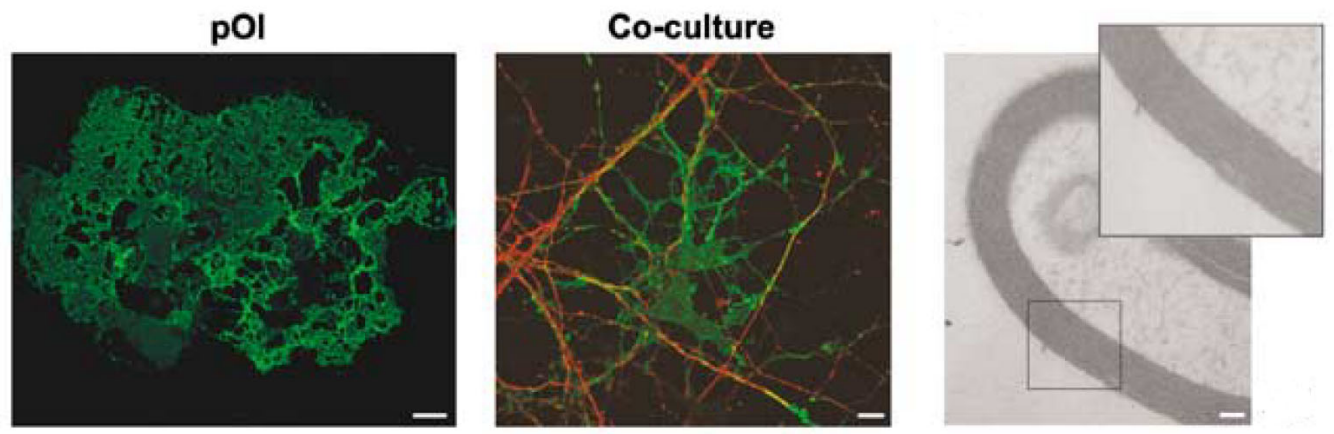

Abbildung 1: Oligodendrogliale Zellen differenzieren unter Kulturbedingungen zu reifen Oligodendrozyten und beginnen neuronale Zellfortsätze zu myelinisieren. (A) Immunzytochemische Färbungen einer Oligodendrozyten-Monokultur (pOI) und einer neuroglialen KoKultur (Co-culture). MBP in grün und Beta-3-Tubulin als neuronaler Marker in rot, Balken entspricht 10 $\mu \mathrm{m}$. (B) Elektronenmikroskopische Aufnahme einer 5 Tage alten Ko-Kultur, Nachweis von myelinisierten Axonen, Balken entspricht 100 nm. Modifiziert aus Fitzner et al., 2006.

Im Folgenden wurden sowohl in der Mono- als auch in der Ko-Kultur immunzytochemische Färbungen der Myelinproteine MBP und PLP sowie des im Myelin angereicherten Lipids Galactosylceramid durchgeführt. Hierbei zeigte sich, dass in Anwesenheit von Neuronen eine Umverteilung dieser Moleküle stattfand, die sich in einer zunehmenden Ko-Lokalisierung der Epitope bemerkbar machte. 

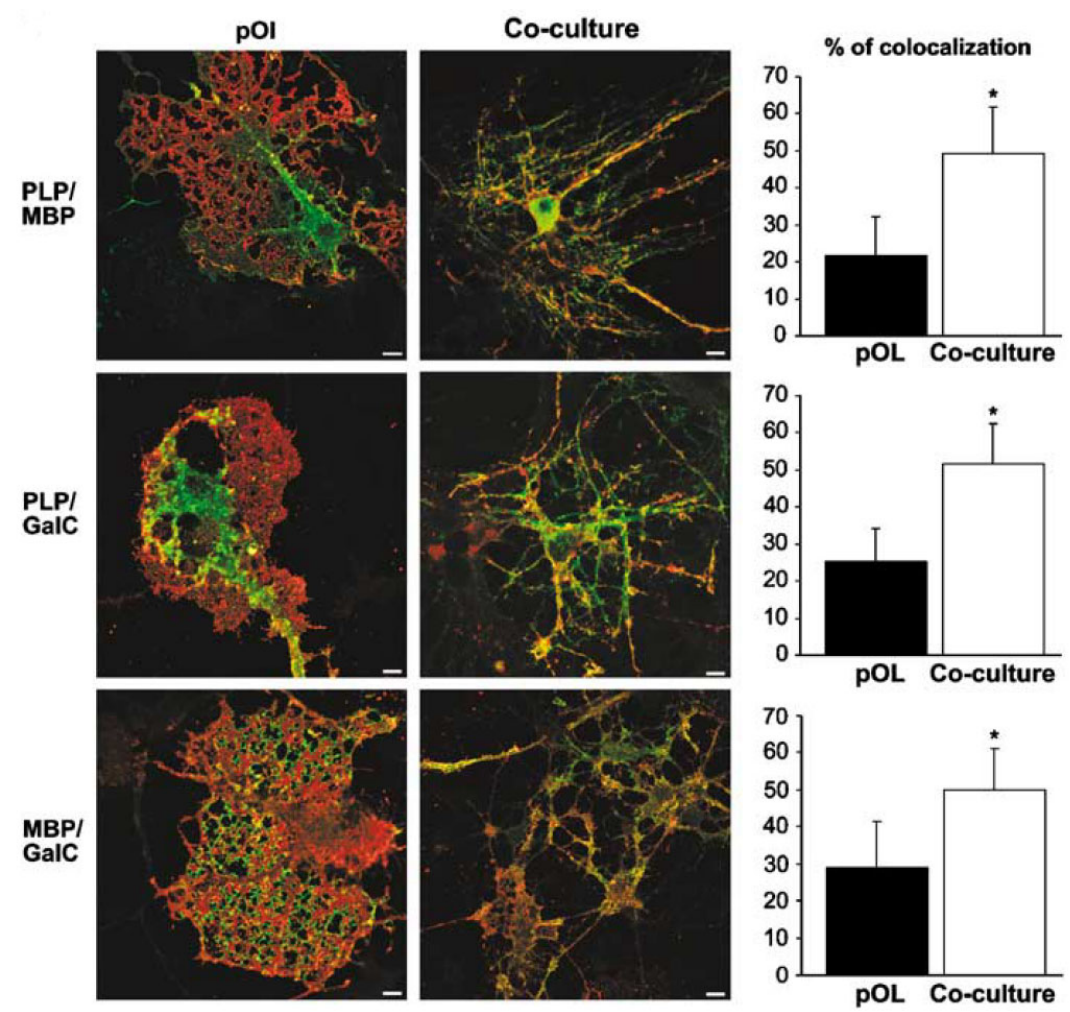

Abbildung 2: Die Anwesenheit von Neuronen in einer Oligodendrozyten-Kultur führt zu einer zunehmenden Ko-Lokalisation bestimmter Proteine und Lipide. Immunzytochemische Färbung von PLP (grün), GalC (rot) und MBP (rot in der oberen, grün in der unteren Bildreihe), quantitative Auswertung der Ko-Lokalisation der Epitope $(\mathrm{n}=20$ Zellen, in $\% \pm$ Standardabweichung, *signifikanter Unterschied zur Kontrolle, $\mathrm{P}<0,001)$, Balken entspricht $10 \mu \mathrm{m}$. Modifiziert aus Fitzner et al., 2006.

3.2 Nach Ko-Kultivierung von Oligodendrozyten mit Neuronen findet sich eine Anreicherung der Myelinproteine MBP und PLP in spezifischen Membrandomänen.

Die Membraneigenschaften neuroglialer Ko-Kulturen können biochemisch analysiert werden. Die Löslichkeit von Membranen bzw. Membrandomänen in bestimmten Lösungsmitteln kann Hinweise auf den Ordnungsgrad der Membran liefern (Schroeder R et al. 1994). Sind Proteine mit bestimmten Membrandomänen assoziiert, verhält sich ihre Löslichkeit im Detergenz dann entsprechend der Membrandomäne (Simons K und Ikonen E 1997).

Zur Analyse oligodendroglialer Membranen wurde das Lösungsmittel CHAPS (Abkürzung für 3-[(3-cholamidopropyl)dimethylammonio]-1-propanesulfonat) verwendet, in dem flüssig-geordnete Membrandomänen eine geringe Löslichkeit besitzen. Hierbei konnte gezeigt werden, dass sich nach Ko-Kultur mit Neuronen ein 
größerer Teil der Proteine PLP und MBP in Assoziation mit der CHAPS-unlöslichen Membranfraktion fand als in einer Oligodendrozyten-Monokultur.

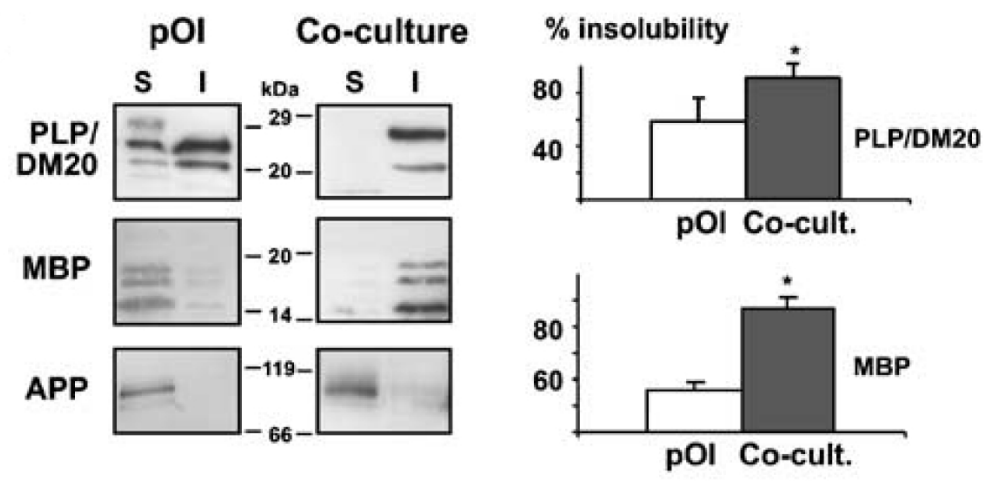

Abbildung 3: In der neuroglialen Ko-Kultur findet sich eine zunehmende CHAPS-Unlöslichkeit von PLP und MBP. Quantitative Analyse der CHAPS-Iöslichen (S) und der -unlöslichen (I) Fraktionen von Lysaten der Monokultur (pOl) bzw. der Ko-Kultur (Co-Culture). Western-Blot mit Nachweis von PLP und seiner Isoform DM20 (PLP/DM20) sowie MBP und APP (engl. „amyloid precursor protein“). Modifiziert aus Fitzner et al., 2006.

Das in der Myelinmembran angereicherte Glycosphingolipid Galactosylceramid fand sich insbesondere in flüssig-geordneten und somit CHAPS-unlöslichen Membrandomänen. Durch Behandlung mit Fumonisin B1 wird die Sphingolipidsynthese der Zelle reduziert (Stockmann-Juvala $\mathrm{H}$ und Savolainen K 2008), was im Falle der Oligodendrozyten zur Reduktion der GalC-Konzentration in der Membran führte. Ein Abfall der GalC-Menge in der Membran resultierte in einer Abnahme des MBP-Gehaltes in der CHAPS-unlöslichen Membranfraktion. Des weiteren ließ sich zeigen, dass der Hauptanteil der Lipide der reifen Myelinmebran, die aus Hirnen adulter Mäuse extrahiert werden kann, CHAPS-unlöslich war, wohingegen die Membran von kultivierten Oligodendrozyten in Abwesenheit von Neuronen nur zu einem Teil CHAPS-unlöslich war. 


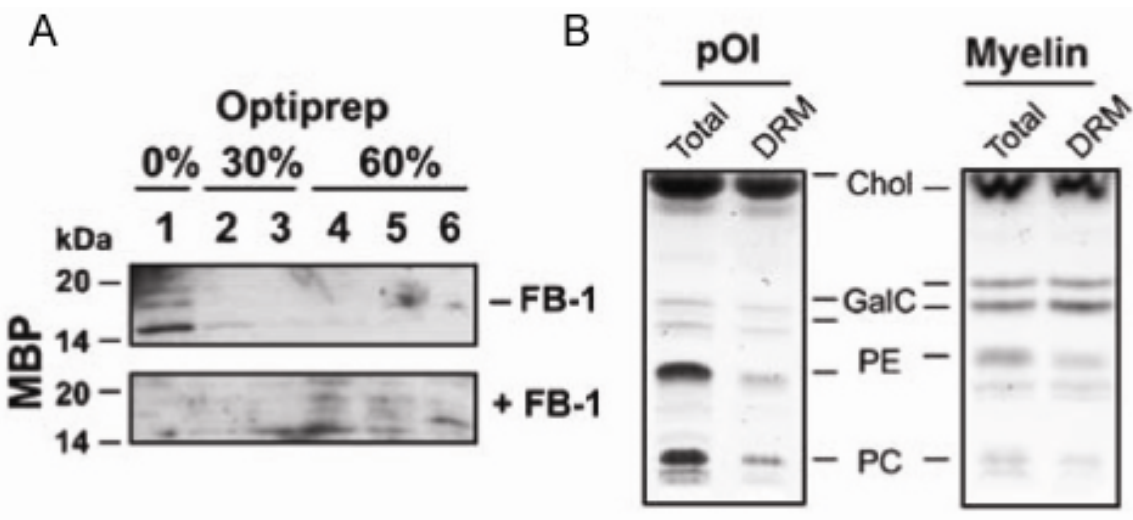

Abbildung 4: Reduktion der GalC-Konzentration in der oligodendroglialen Membran führt zu einer Abnahme der MBP-Menge in der CHAPS-unlöslichen Fraktion. Der Anteil CHAPSunlöslicher Lipide im Myelin ist größer als in den Zellen einer Oligodendrozyten-Monokultur. (A) Western-Blot der MBP-Menge in den verschiedenen Fraktionen eines Optiprep-Gradienten (1-6) nach CHAPS-Extraktion (mit oder ohne Fumonisin B1 - FB-1), Fraktion 1 zeigt den CHAPSunlöslichen Anteil. (B) Dünnschicht-Chromatographie der Lipide einer Oligodendrozyten-Monokultur $(\mathrm{pOL})$ und der Myelinlipide. Hierbei ist jeweils die gesamte Lipidmenge gegen den CHAPS-unlöslichen Anteil DRM (engl. „detergent resitant membrane“) aufgetragen. Cholesterin - Chol, Galactosylceramid - GalC, Phosphatidylethanolamin - PE, Phosphatidylcholin - PC. Modifiziert aus Fitzner et al., 2006.

3.3 In Anwesenheit von Neuronen findet sich eine Zunahme des Ordnungsgrades der oligodendroglialen Membran.

Neben biochemischen Verfahren können auch mikroskopische Techniken zur Analyse der Membranstruktur eingesetzt werden. Zur mikroskopischen Darstellung der Membranordnung von Oligodendroyzten wurde der sog. Laurdan-Farbstoff (Eigenname für 6-Dodecanoyl-2-Dimethylaminonaphthalen) verwendet, dessen Emissionsspektrum sich in Abhängigkeit der Lipidordnung der Phosphlipide einer Membran verändert (Gaus K et al. 2006). Als Ergebnis der Messungen lässt sich ein GP-Wert bestimmen (engl. "generalized polarization"). Regionen der Membran mit hohen GP-Werten haben einen hohen Ordnungsgrad. In dieser Arbeit konnte gezeigt werden, dass die Zellmembran von Oligodendrozyten in Mono-Kultur nur kleine Bereiche mit höheren GP-Werten aufwies. 

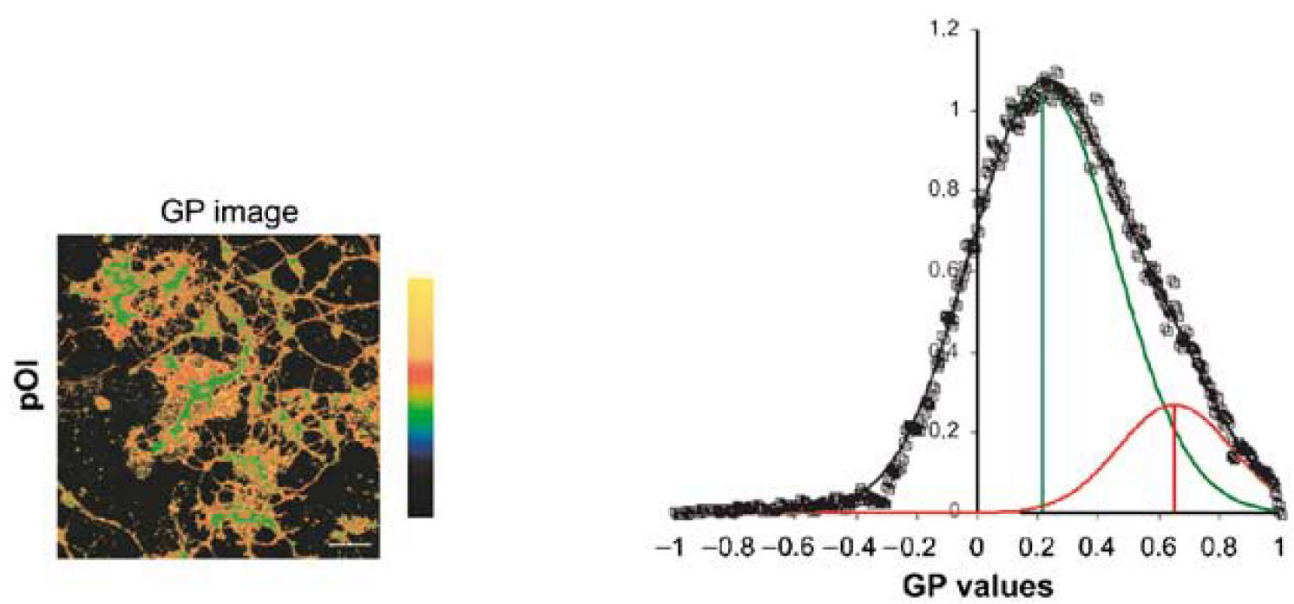

\begin{abstract}
Abbildung 5: Die Zellmembran von Oligodendrozyten einer Monokultur weist nur wenige kondensierte Bereiche auf. Verteilung der GP-Werte (GP values) in der Zellmembran von Oligodendrozyten einer Monokultur (pOI). Pseudofarben kodieren die GP-Werte der Zellmembranen einer Monokultur, hierbei entsprechen niedrige GP-Werte einer weniger kondensierten Membran und werden durch grüne Farbe dargestellt, wohingegen gelbe Farbe im Spektrum einer kondensierten Membran entspricht. Modifiziert aus Fitzner et al., 2006.
\end{abstract}

Wurde zusätzlich immunzytochemisch Galactosylceramid in der Zellmembran angefärbt, so zeigten GalC-gefärbte Bereiche der Zellmembran von Oligodendrozyten in Monokultur keine erhöhten GP-Werte. In Ko-Kulturen mit Neuronen wiesen die GalC-positiven Membranabschnitte der oligodendroglialen Membran jedoch deutlich erhöhte GP-Werte auf, was auf eine höhere Ordnung innerhalb der Membran hinwies. Es konnte außerdem gezeigt werden, dass der neuronale Effekt auf die Organisation der Oligodendrozyten-Membran im vorliegenden Model nicht von einem unmittelbaren Zell-Zell-Kontakt abhängig war, sondern durch unbekannte lösliche neuronale Faktoren vermittelt wurde. 

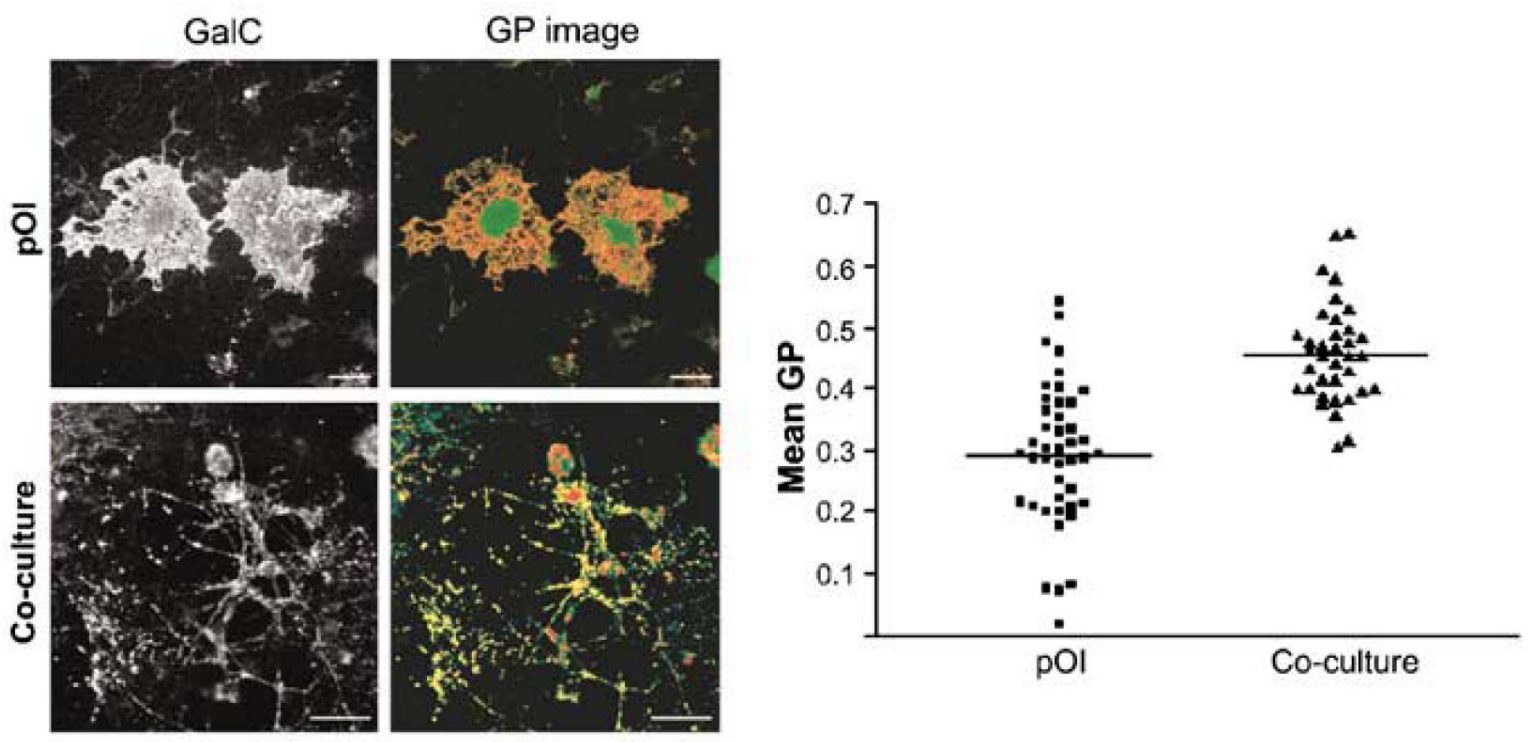

Abbildung 6: In Anwesenheit von Neuronen findet sich eine zunehmende Kondensation der oligodendroglialen Membran. Darstellung der GP-Werte GalC-positiver Membranbereiche in Pseudofarben, hierbei entspricht gelbe Farbe einer stärker kondensierten Membran mit höheren GPWerten. Vergleich der GP-Werte einer Oligodendrozyten-Monokultur (pOI) und einer Ko-Kultur (Coculture). Im Diagramm sind die GP-Mittelwerte (Mean GP) von jeweils 30 Zellen dargestellt, Balken entspricht $25 \mu \mathrm{m}$. Modifiziert aus Fitzner et al., 2006.

3.4 Neurone induzieren die Bildung von mobilen Galactosylceramid-Clustern in der oligodendroglialen Membran.

Mit Hilfe der sog. TIRF-Mikroskopie (engl. "total internal reflection fluorescence") können immunzytochemisch gefärbte Membranbestandteile, die sich in unmittelbarer Nähe zur Glasoberfläche des Objektträgers befinden, auch in lebenden Zellen abgebildet und verfolgt werden (Fish KN 2001). In Gegenwart von Neuronen ließ sich hierbei eine zunehmende Größe sogenannter GalC-Cluster, also fokaler Ansammlungen von GalC-Molekülen in der oligodendroglialen Membran, spezifischer im äußeren Leaflet des Bilayers, nachweisen. Hierbei zeigte sich nach Untersuchung dieser Cluster mit dem Laurdan-Farbstoff ein erhöhter GP-Wert und somit eine höhere Membranordnung innerhalb der Membrandomänen. Die Cluster waren innerhalb der Membran mit unterschiedlichen Diffusionskoeffizienten mobil. Zusätzlich wurde das Diffusionsverhalten der GalC-gefärbten Membran durch FRAP (engl. "fluorescence recovery after photobleaching") untersucht (Reits EAJ und Neefjes JJ 2001). Hierbei wurden mit einem GalC-Antikörper gefärbte lebende Oligodendrozyten (mit oder ohne Neuronen) in einem umschriebenen Areal der 
Zelloberfläche mit einem Laserimpuls hoher Energie bestrahlt und so die Fluorophore in diesem Bereich gebleicht. Hiernach wurden die Zellen über einen mehrere Minuten langen Zeitraum mikroskopisch verfolgt. Aus der Geschwindigkeit der Wiederaufüllung des gebleichten Areals mit gefärbten GalC-Molekülen lies sich ein Diffusionskoeffizient errechnen. Es konnte gezeigt werden, dass die GalC-Diffusion in der oligodendroglialen Membran im Beisein von Neuronen schneller war, als in der Oligodendrozyten-Monokultur. Die aus den beiden Methoden TIRF und FRAP errechneten Diffusionskoeffizienten lagen in einer ähnlichen Größenordnung.

A
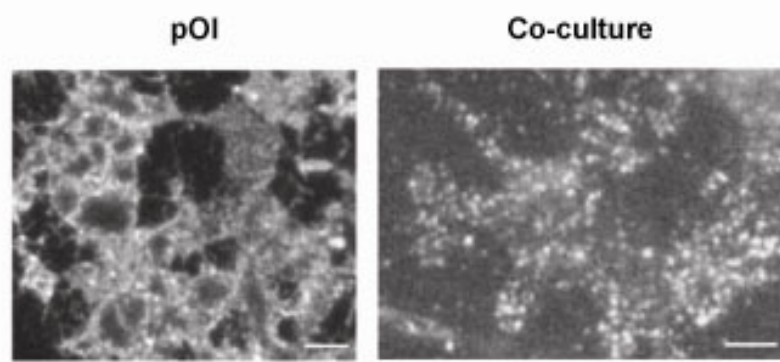

B
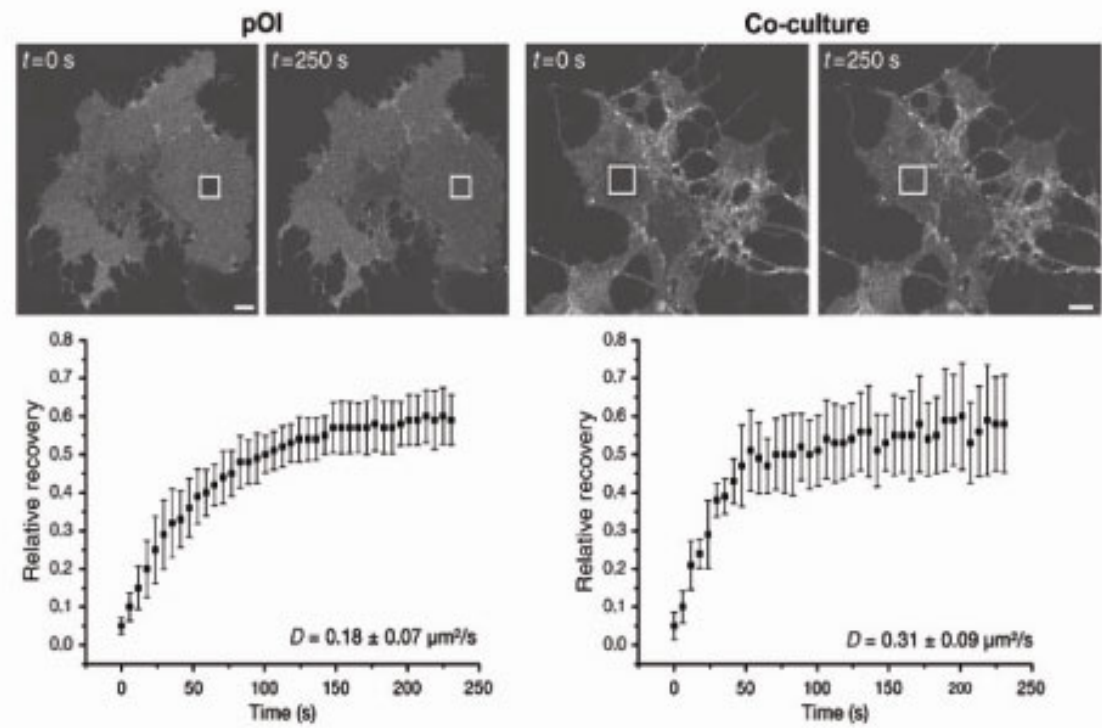

Abbildung 7: Neurone induzieren die Bildung mobiler GalC-Cluster in der oligodendroglialen Membran. (A) Darstellung der GalC-gefärbten oligodendroglialen Membran einer Mono- (pOl) und einer Ko-Kultur (Co-culture) mittels TIRF-Mikroskopie. (B) FRAP-Mikroskopie der Mono- und KoKultur. Immunzytochemische Anfärbung von GalC. Exemplarisch sind Zellen zu zwei verschiedenen Zeitpunkten (0 s und $250 \mathrm{~s}$ nach dem bleichenden Laserimpuls abgebildet). Quantifizierung der Wiederauffüllung des gebleichten Areals mit gefärbten GalC-Molekülen. Dargestellt ist der Anteil der Wiederauffüllung (relative recovery) in Abhängigkeit der Zeit nach Beendigung des bleichenden Laserimpulses. Hieraus lässt sich der Diffusionskoeffizient D errechnen, Balken entspricht $10 \mu \mathrm{m}$. Modifiziert aus Fitzner et al., 2006. 
Um die Bildung von GalC-Clustern weiter zu charakterisieren, wurde zusätzlich die Methode der STED-Mikroskopie verwendet. Diese Technik ermöglicht eine deutliche Verbesserung der räumlichen Auflösung in der Fluoreszenz-basierten Mikroskopie. Hiermit können zwei Punkte noch bis zu einem minimalen Abstand von ca. 60-70nm differenziert werden (Willig $\mathrm{KI}$ et al. 2006). Hierbei ergab sich, dass die KoKultivierung von Oligodendrozyten mit Neuronen zur verstärkten Bildung größerer GalC-Cluster führte.

Zusätzlich konnte mit Hilfe der FRET-Mikroskopie (engl. "fluorescence resonance energy transfer"; (Pietraszewska-Bogiel A und Gadella TWJ 2011)) gezeigt werden, dass sich im Beisein von Neuronen GalC-Moleküle in der oligodendroglialen Membran aneinander annäherten, also dichter gepackt bzw. kondensiert waren. Hierbei wurde zunächst eine definierte Menge von GalC-Antikörpern zur Hälfte mit dem Суз- und zur anderen Hälfte mit dem Cy5-Fluorophor markiert. Die Mischung aus unterschiedlich markierten Antikörpern wurde schließlich zur immunzytochemischen Färbung von Oligodendrozyten verwendet. Befanden sich nun zwei unterschiedlich markierte GalC-Moleküle in unmittelbarer Nähe zueinander, trat bei entsprechender Anregung eines Fluorophors, eines Donors, eine Veränderung des Anregungszustandes des anderen Fluorophors, des Akzeptors ein, die dann mikroskopisch gemessen werden konnte. 
A
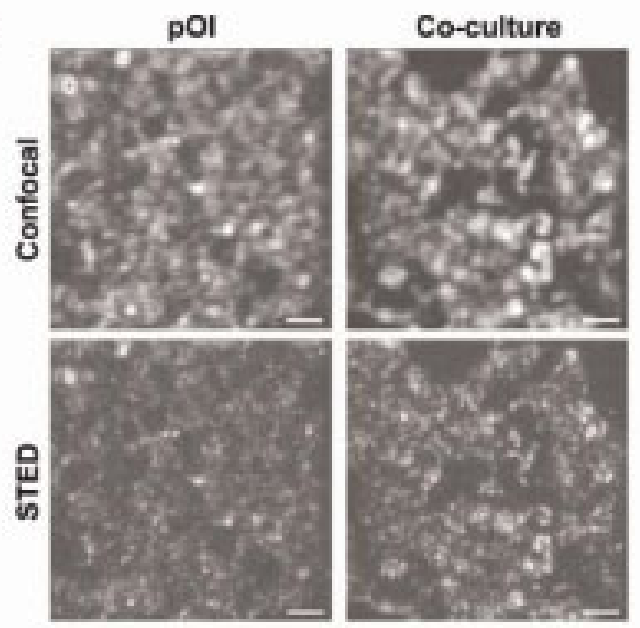

B
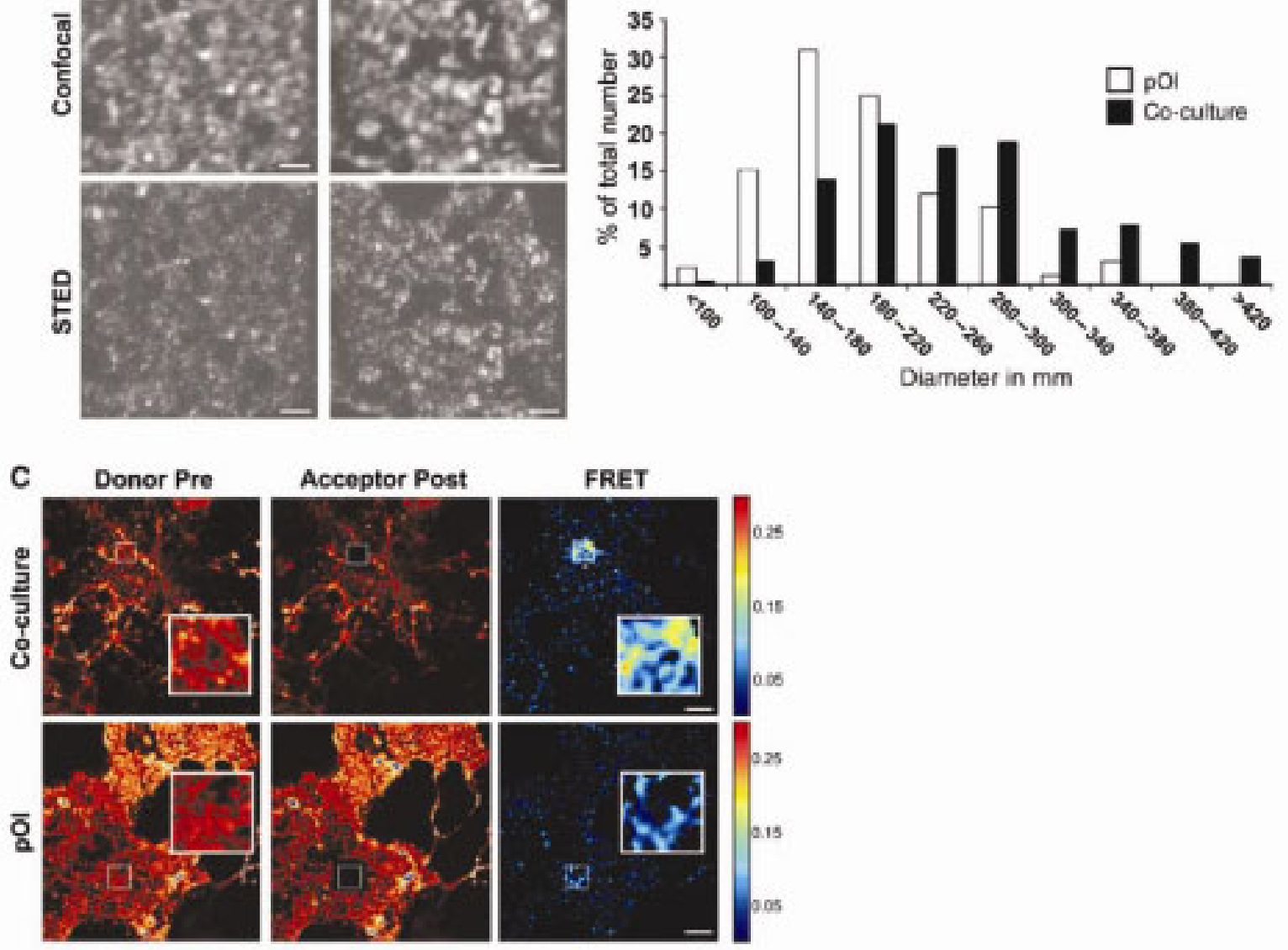

Abbildung 8: In Anwesenheit von Neuronen steigt die Größe der in der oligodendroglialen Membran nachweisbaren GalC-Cluster. (A) Immunzytochemische Färbung der GalC-Anteile der oligodendroglialen Membran in einer Mono- (pOI) und einer Ko-Kultur (Co-culture), Darstellung mittels konfokaler Lasermikroskopie oder mittels STED-Mikroskopie, Balken entspricht $1 \mu \mathrm{m}$. (B) Quantifizierung der Größe der GalC-Cluster in Mono- und Ko-Kulturen, dargestellt ist die Häufigkeit der Cluster mit einem definierten Durchmesser in Millimetern. (C) Darstellung des FRET-Signals der oligodendroglialen Membran nach immunzytochemischer Färbung von GalC-Molekülen als Donor und Akzeptor. In der rechten Bildreihe ist die FRET-Effizienz in Pseudofarben dargestellt. Verglichen werden erneut Mono- und Ko-Kultur, Balken entspricht $10 \mu \mathrm{m}$. Modifiziert aus Fitzner et al., 2006.

3.5 Die Umstrukturierung der oligodendroglialen Membran nach KoKultivierung mit Neuronen ist MBP-abhängig.

Primäre oligodendrogliale Kulturen können auch aus Hirnen der MBP-depletierten Maus-Mutante Shiverer generiert werden. Hierbei ließen sich in der Zellmembran von Shiverer-Oligodendrozyten in neuroglialen Ko-Kulturen im Vergleich zu WildtypOligodendrozyten nur wesentlich kleinere Galc-Cluster nachweisen. Die Clustergröße in Shiverer-Oligodendrozyten konnte gesteigert werden, indem MBP exogen in den 
Zellen exprimiert wurde. Hierzu wurde basierend auf dem Semliki-Forest-Virus (SFV) ein virales Konstrukt erstellt, das die genetische Information eines MBP-EYFPFusionsproteins enthält. EYFP steht hierbei für das gelb fluoreszierende Protein (engl. „enhanced yellow fluorescent protein“), dessen Expression in einer Zelle lichtmikroskopisch dargestellt werden kann. Infizierte ein solcher Virus einen Oligodendrozyten, führte dies zur Expression des Fusionsproteins mit einer funktionalen MBP-Domäne und einem EYFP-Anteil. Dieses Fusionsprotein verhielt sich in der Zelle ähnlich wie die Wildtyp-Variante, zeigte also die gleiche Assoziation zur Membran reifer Oligodendrozyten und zur Myelinmembran. In Beisein von Neuronen führte dieses Konstrukt in Shiverer-Oligodendrozyten zu einer Größenzunahme von GalC-Clustern. Ähnliche Experimentmit PLP-depletierten Oligondrozyten ergaben, dass das Ausmaß der PLP-Expression keinen wesentlichen Einfluss auf die GalC-Clusterbildung hatte.

Zusätzlich konnte nachgewiesen werden, dass in Shiverer-Oligodendrozyten einer neuroglialen Ko-Kultur die mit Hilfe des Laurdan-Farbstoffes gemessenen GP-Werte im Vergleich zu Wildtyp-Oligodendrozyten niedriger waren und somit in der Mutante eine weniger ausgeprägte Membrankondensation nachweisbar war. Dies konnte zusätzlich auch anhand biochemischer Extraktionsversuche bestätigt werden. 
A
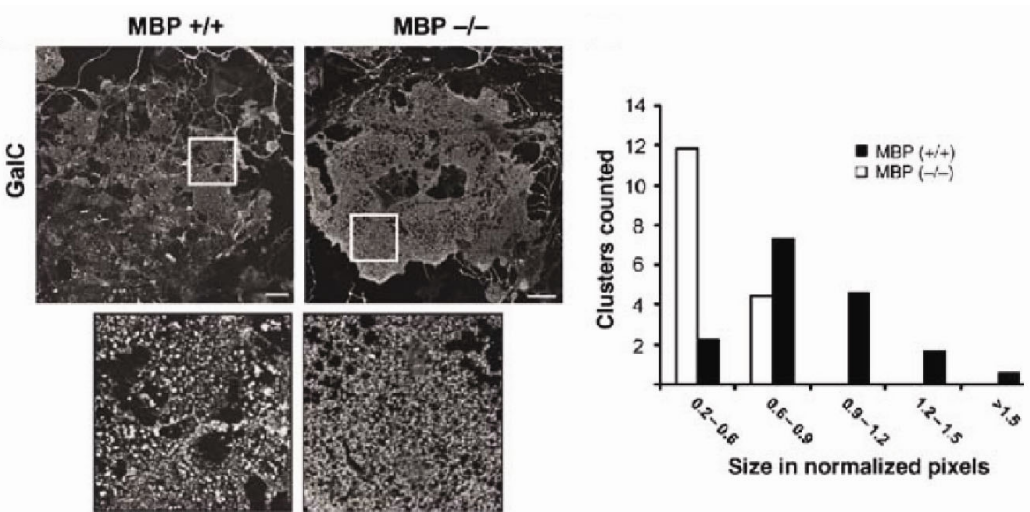

B

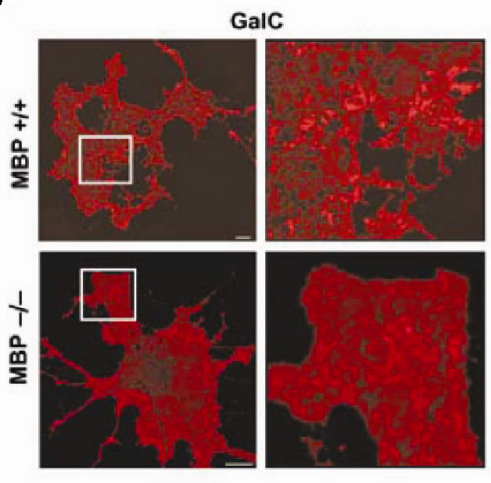

MBP $-I-+$ SFV/MBP

C
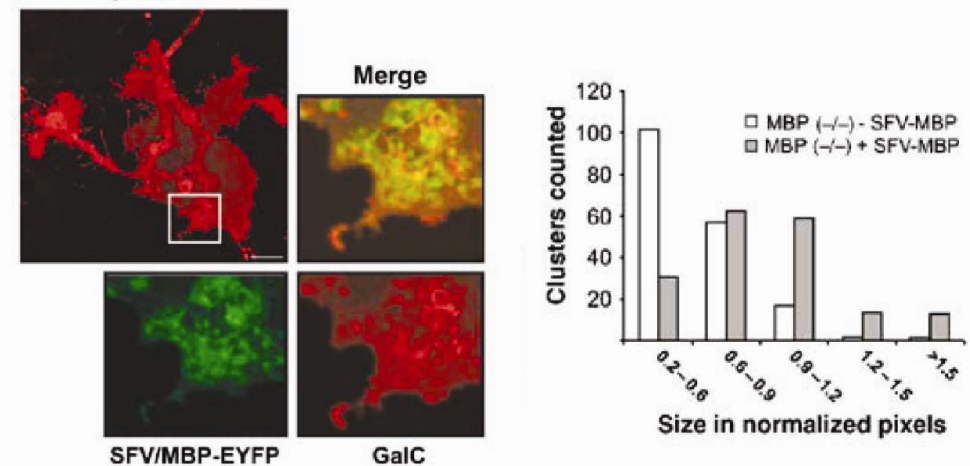

D
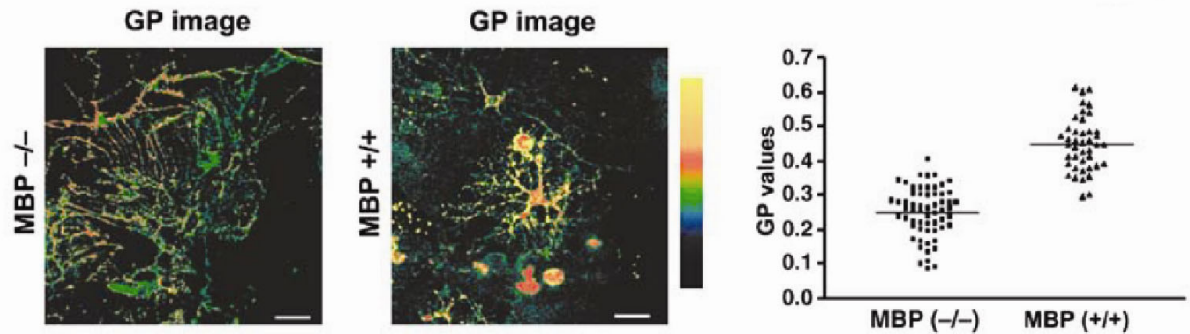

Abbildung 9: Die Umstrukturierung der oligodendroglialen Membran in MBP-abhängig. (A) Immunzytochemische Färbung von GalC der oligodendroglialen Membran von fixierten Wildtyp- (MBP $+/+$ ) oder Shiverer-Oligodendrozyten (MBP -/-), Quantifizierung der Größe der GalC-Cluster, Balken entspricht $20 \mu \mathrm{m}$. (B) Immunzytochemische Färbung von GalC in der Membran lebender Wiltyp- (MBP $+/+$ ) oder Shiverer-Oligodendrozyten (MBP -/-), Infektion von Shiverer-Oligodendrozyten mit einem Semliki-Forest-Virus der das Fusionsprotein MBP-EYFP transferiert (SFV/MBP-EYFP), die Expression des Fusionsproteins ist durch Abbildung von EYFP bestätigt, Balken entspricht $10 \mu \mathrm{m}$. (C) Quantifizierung der GalC-Clustergröße in der Zellmembran von Shiverer-Oligodendrozyten mit oder ohne Infektion durch SFV/MBP-EYFP. (D) Abbildung und Quantifizierung der GP-Werte von Wildtyp(MBP +/+) oder Shiverer-Oligodendrozyten (MBP -/-). Modifiziert aus Fitzner et al., 2006. 


\section{Diskussion}

Myelin ist eine Membran, die sich in vielerlei Hinsicht von anderen Zellmembranen unterscheidet. Zunächst finden sich in Proteomanalysen zwar zahlreiche Proteine, jedoch fallen ca. 80\% der gesamten Proteinmasse auf die zwei Proteine MBP und PLP. Darüber hinaus zeigt sich eine hochgradige Anreicherung von Lipiden in der kompakten Struktur des Myelins, so dass der Lipidanteil ca. $70-80 \%$ des Trockengewichtes ausmacht. Auffällig ist hierbei die hohe Konzentration von Cholesterol sowie der Glycosphingolipide Galactosylceramidund Sulfogalactosylceramid (Baumann N und Pham-Dinh D 2001). Diese Lipidkomposition führt zu einer ausgesprochenen Membrankondensation, also einer dichten Packung der Lipidmoleküle innerhalb der Membran (Gaus K et al. 2005). Auch in anderen Zellsystemen finden sich Membranen oder Membrandomänen mit einem erhöhten Anteil der genannten Lipide. Insbesondere die apikale, also die dem Lumen zugewandte Fläche von Epithelzellen, enthält gehäuft derartige Membrankomponenten. Anfänglich wurde daher nach Untersuchung der epithelialen Zellmembran der Begriff des "Raft“ geprägt, einer Membrandomäne, die sich durch eine bestimmte Lipidzusammensetzung und Anreicherung spezifischer Proteine definiert und zusätzlich typische biophysikalische Eigenschaften aufweist. Diese Membrandomäne wurde zunächst unter anderem durch ihre Lösungseigenschaft in nicht-ionischen Detergenzien charakterisiert (Füllekrug J und Simons K 2004). Es konnte gezeigt werden, dass auch die Myelinmembran Domänen enthält, die sich durch ihre Unlöslichkeit in entsprechenden Lösungsmitteln wie z.B. CHAPS und durch eine Assoziation mit bestimmten z.B. GPI-verankerten Proteinen auszeichnen (Simons $M$ et al. 2000). Ein großes Hindernis in der Untersuchung von sog. RaftDomänen in einer Membran ist nicht nur ihre geringe Größe (10-200nm) sondern auch ihre sehr dynamische metastabile Natur (Shaw AS 2006).

In der vorliegenden Arbeit wurde versucht, die Umstrukturierung der Oligodendrozytenmembran im Laufe der Myelinisierung zu untersuchen und zu beschreiben. Hierbei stellt sich die Frage, ob sich die einmalige Struktur und Komposition der homogenen kondensierten Myelinmembran in strukturellen Besonderheiten der Zellmembran kultivierter Oligodendrozyten widerspiegelt. Zusätzlich wurde untersucht, ob sich diese Membraneigenschaften in Gegenwart von Neuronen, also mit potentiellem Beginn der Myelinisierung, verändern. 
Mit Hilfe verschiedener biochemischer und mikroskopischer Methoden konnte gezeigt werden, dass sich in der oligodendroglialen Membran Cluster des Lipids GalC finden, deren Größe in Anwesenheit neuronaler Faktoren zunahm. Hierbei war zu beobachten, dass sich die Membran innerhalb dieser GalC-Cluster zunehmend kondensierte und eine höhere Ordnung aufwies, was z.B. durch die Verwendung des Farbstoffes Laurdan nachgewiesen werden konnte. Es konnte außerdem gezeigt werden, dass diese Umstrukturierung wesentlich von der Präsenz des Proteins MBP in den Zellen abhängig war.

Es stellt sich die Frage, wie dieser Clustering-Prozess innerhalb der oligodendroglialen Membran erreicht wird. Hierbei besteht die Möglichkeit, dass sich die Vergrößerung der GalC-Cluster durch ein Zusammenfließen von in der Membran bereits präexistierenden kleineren Einheiten bzw. Domänen ergibt. Unter Verwendung des Laurdan-Farbstoffes konnte gezeigt werden, dass die Cluster eine kondensierte und geordnete Membran aufwiesen. Kleinere Einheiten einer solchen Membrandomäne sollten entsprechende biophysikalische Eigenschaften innehaben. Die Detektion dieser Membranbereiche mittels Laurdan ist jedoch durch die Auflösungsgrenze der Lichtmikroskopie von ca. $200 \mathrm{~nm}$ limitiert und kann deshalb nicht in der Analyse beliebig kleiner Domänen der Membran angewendet werden. Im Gegensatz hierzu bildet die Methode FRET Wechselwirkungen zwischen einzelnen markierten Molekülen ab und erlaubt daher auch die Abbildung von im Nanobereich stattfindenden Prozessen (Pietraszewska-Bogiel A und Gadella TWJ 2011). In der vorliegenden Arbeit konnte gezeigt werden, dass sich ein signifikantes FRET-Signal nur nach neuronalem Einfluss auf die Oligodendrozyten-Membran nachweisen ließ, was gegen das Vorliegen bereits vorbestehender lichtmikroskopisch nicht abzubildender kondensierter Membrankomplexe spricht. Generell muss jedoch angemerkt werden, dass derartige Komplexe zusätzlich sehr dynamisch sein können und sich deshalb unter Umständen bei zu geringer zeitlicher Auflösung der Abbildung entziehen (Shaw AS 2006).

Darüber hinaus ergab die Untersuchung der oligodendroglialen Membran mit der TIRF-Mikroskopie, dass die in Anwesenheit von Neuronen vergrößerten GalCCluster mobil waren. Man könnte sich also vorstellen, dass diese mobilen Domänen zu größeren homogenen Membraneinheiten „zusammenfließen“. 
Neben Veränderungen der Lipidkomposition einer Membran können auch die mit der Membran assoziierten Proteine die Membranstruktur modulieren. So konnte gezeigt werden, dass bestimmte Proteine kondensierte Membranbereiche stabilisieren oder gar deren Bildung initiieren (Viola A und Gupta N 2007). Diese Proteine binden mit basischen, also positiv geladenen Abschnitten ihrer Aminosäuresequenz an das negativ geladene innere Leaflet der Membran oder interkalieren über hydrophobe Fettsäuremodifikationen wie z.B. Myristate in die hydrophoben Anteile der Membran. Beispiele für derartige Proteine sind „GAP43“-ähnliche Proteine (engl. „Growth Associated Protein 43"), die z. B. in Immunzellen T-Zellrezeptoren an der Zelloberfläche durch Clustering der entsprechenden Membrandomänen zu einer sogenannten immunologischen Synapse zusammenführen (Tong $\mathrm{J}$ et al. 2008). Auch MARCKS (engl. „myristoylated alanine-rich C-kinase substrate“), ein Substrat der Proteinkinase $\mathrm{C}$ bindet über elektrostatische Wechselwirkungen an die zytosolische Seite der Membran und bewirkt das Zusammenführen spezifischer Lipide, in diesem Fall von Phosphatidylinositolen, des zytoplasmatischen Leaflets. Die hierbei entstehenden Membrandomänen sind aufgrund ihrer Größe dann auch lichtmikroskopisch nachweisbar (Laux T et al. 2000).

Interessanterweise finden sich in der Aminosäuresequenz des basischen Myelinproteins MARCKS-ähnliche Sequenzen (Harauz G et al. 2000). Hierbei konnte in zahlreichen in vitro Studien gezeigt werden, dass das Protein sowohl über elektrostatische als auch über hydrophobe Wechselwirkungen mit Membranen interagiert und sich in der Art eines peripheren Membranproteins, also ohne eine eigentliche Transmembrandomäne, an diese anlagert (Min Y et al. 2009; Nawaz S et al. 2009). Da MBP diese Wechselwirkungen nicht nur innerhalb begrenzter Domänen, sondern eher über seine gesamte Länge eingeht, wird angenommen, dass das Protein wesentlich daran beteiligt ist, in der kompakten Struktur des Myelins die beiden opponierenden zytoplasmatischen Leaflets in unmittelbare Nähe zueinander zu bringen. In Analogie zu der Funktion von MARCKS könnte man sich jedoch auch ein Zusammenführen, also Clustern von Membrandomänen innerhalb einer Membran vorstellen. Hierfür sprechen die aus der Untersuchung der ShivererKo-Kultur gewonnenen Ergebnisse. Fehlt das Protein MBP, führen neuronale Faktoren nicht mehr zu einer Größenzunahme der GalC-Cluster und auch die Veränderung der Membranordnung im Sinne einer zunehmenden Membrankondensation bleibt aus. 
Selbstverständlich ergibt sich die Frage, wie MBP bei Anheftung an die negativ geladenen Lipide des zytoplasmatischen Leaflets zum Clustering von Lipiden, im vorliegenden Fall von GalC, im äußeren Leaflet der Membran führen kann. Hierzu ist zu erwähnen, dass die beiden Lipid-Lagen einer Bilayer-Membran nicht ohne jede Verbindung zueinander sind (Perlmutter JD und Sachs JN 2011). Bei entsprechender Länge des hydrophoben Schwanzteiles eines Lipids kann dieser in die gegenüberliegende hydrophobe Region des anderen Leaflets interkalieren und so zu einer Art Verzahnung führen. Die Frage nach derartigen Wechselwirkungen zwischen den beiden Leaflets konnte bisher auch in anderen Zellsystemen nicht abschließend beantwortet werden. Es gibt jedoch Hinweise, dass ein durch Antikörper artifiziell verursachtes Clustering von GalC auf Zelloberfläche von Oligodendrozyten zur Ansammlungen von MBP an der Innenseite der Zellmembran führt (Dyer CA und Benjamins JA 1989). Dies könnte als Hinweis auf eine Interaktion von GalCDomänen im äußeren mit Lipiden des cytoplasmatischen/inneren Leaflets gewertet werden.

Die Tatsache, dass MBP alleine in einer Oligodendrozytenkultur ohne Vorhandensein neuronaler Signale noch nicht zu einer messbaren Vergrößerung von GalC-Clustern führt, könnte auf zusätzlich notwendige Modifikationen des Proteins hinweisen. Es ist bekannt, dass MBP durch eine Vielzahl posttranslationaler Modifikationen in seiner Struktur verändert werden kann (Harauz G und Libich DS 2009). Das Muster dieser Modifikationen unterscheidet sich Z.B. in der Phase der frühen Myelinisierung von späteren Phasen der Entwicklung. Zusätzlich scheinen auch krankhafte Prozesse wie z.B. die demyelinisierende Erkrankung Multiple Sklerose Einfluss auf die posttranslationale Prozessierung des Proteins zu haben. Im Rahmen der Modifikation können dem Protein hierbei auch Elemente angelagert werden, die dessen Interaktion mit der Membran verändern. Durch posttranslationale Prozessierung können die Ladungseigenschaften des Proteins und somit dessen Affinität zur Membran beeinflusst werden (Harauz G et al. 2004). Es konnte außerdem gezeigt werden, dass Teile des Proteins regelrecht in das innere Leaflet penetrieren. Es lässt sich vermuten, dass hierdurch auch die Struktur der Membran beeinflusst wird. Könnten solche posttranslationalen Veränderungen in Abhängigkeit neuronaler Signale reguliert werden, wäre dies ein denkbarer Mechanismus zur Veränderung oder Stabilisierung der Membranbeschaffenheit. Daneben könnte es durch Einfluss neuronaler Faktoren auf Oligodendrozyten auch zur Expression 
weiterer Proteine kommen, die auf eine bisher nicht bekannte Weise die Umstrukturierung der Membran direkt oder indirekt z.B. durch einen MBPvermittelten Effekt steuern.

Natürlich liegt es nahe, dass die Umstrukturierung einer Membran auch Folge einer Veränderung ihrer Lipidkomposition sein kann. Zellen zeigen in Abhängigkeit ihrer Funktion eine große Variabilität der Lipidzusammensetzung ihrer Membranen. Es erscheint logisch, dass diesen Unterschieden Steuermechanismen zu Grunde liegen, die Zellen nicht nur einen nach intrinsischen Programmen geregelten Aufbau ihrer Membranen ermöglichen, sondern darüber hinaus auch die Reaktion auf externe Signale zulassen.

Die zum Beispiel in epithelialen Zellmembranen nachweisbaren Lipid-Rafts sind Membranbereiche, die sich von der sie umgebenden Membran durch eine Anreicherung von Sphingolipiden mit längeren gesättigten Fettsäureketten und Cholesterol. Durch Zusammenlagerung dieser Bestandteile entsteht eine Membrandomäne mit hohem Ordnungsgrad und dichter Packung der Lipide. Diese Einheit zeigt die Tendenz, sich aus energetischen Gründen von der umgebenden, weniger geordneten Membran zu separieren und quasi als „Floß“ in ihr zu treiben. Hierbei kann Größe und Dauer des Bestehens dieser Einheit variieren. Steigt nun die Konzentration der den Lipid-Raft aufbauenden Lipide innerhalb der Membran, wird es häufiger zur Bildung entsprechender Domänen kommen, die dann unter Umständen auch eine zunehmende Größe haben. Da Rafts zusätzlich auch mit bestimmten Proteinen assoziiert sind, spielen in diesem Prozess neben Lipid-LipidInteraktionen vermutlich auch Lipid-Protein und Protein-Protein-Interaktionen eine Rolle (Jacobson K et al. 2007).

Ein ähnlicher Prozess könnte auch in der Zellmembran eines Oligodendrozyten stattfinden. Die wesentliche Funktion der oligodendroglialen Membran ist die Bildung einer großflächigen, homogenen, kondensierten Myelin-Membrandomäne in der Umgebung des zu myelinisierenden Axons. Man kann vermuten, dass nur eine derartig strukturierte Membran eine ausreichende Isolation des Axons gewährleistet und so die saltatorische Erregungsleitung ermöglicht. Da Myelin einen entsprechend hohen Anteil an Glycosphingolipiden und Cholesterol enthält, käme auch hier die Möglichkeit in Betracht, das mit Beginn der Myelinisierung und Vorliegen entsprechender aktuell nicht bekannter neuronaler Signale die Synthese dieser 
Membranbestandteile erhöht wird. Erreicht die Konzentration einen kritischen Punkt, könnten sich dann mobile Membrandomänen bilden, die einerseits zunehmend größer werden und zusammenfließen können, andererseits unter Umständen auch stabiler sind, so dass am Ende des Prozesses eine große Myelin-ähnliche Membrandomäne besteht. Wie wichtig diese Eigenschaften der Membrandomäne Myelin sind, wird auch durch die Betrachtung verschiedener Mausmutanten des Lipidstoffwechsels offensichtlich. So führt der Ausfall des Enzyms UDPgalactose:Ceramid Galactosyltransferase zum Erliegen der Galactolipid-Synthese. Dieser Defekt wird jedoch durch die vermehrte Synthese von Glucosylceramid als Ersatz für Galactosylceramid kompensiert (Coetzee $T$ et al. 1996). Das Vorhandensein eines effektiven Kompensationsmechanismus kann hierbei als Hinweis auf die Wichtigkeit des ausgefallenen Prozesses betrachtet werden. Die Regelmechanismen, mit denen Zellen ihre Lipidsynthese äußeren Gegebenheiten anpassen, sind bisher im Detail bekannt.

Es stellt sich zudem die Frage, wie es Oligodendrozyten gelingt, diese hochspezialisierte Membran in der Nähe des Axons, also in der komplexen und kompakten Struktur der Myelinscheide zu lokalisieren und daneben auch eine weniger geordnete und weniger kondensierte Membran im Bereich des Zellkörpers zu erhalten (Aggarwal S et al. 2011). Bei der Betrachtung der oligodendroglialen Membran fällt auf, dass weniger kondensierte bzw. weniger kompakte Bereiche auch mit anderen Proteinen assoziiert sind. Es ist nicht auszuschließen, dass neben den bereits diskutierten Funktionen des MBP weitere Proteine oder Strukturen wie das Zytoskelett jeweils in Abhängigkeit des Entwicklungsstadiums der Zelle Barrieren innerhalb der Zellmembran aufbauen. Zusätzlich liefern neuere Studien Hinweise, dass MBP die oligodendrogliale Membran auch durch Extrusion bestimmter Proteine strukturiert (Aggarwal S et al. 2011).

In der Zukunft wird es spannend sein, die Mechanismen zu untersuchen, mit deren Hilfe Zellen es schaffen, die Struktur ihrer Membranen zum einen der gewünschten Funktion und zum anderen äußeren Umständen anzupassen. 


\section{Literaturverzeichnis}

Aggarwal S, Yurlova L, Simons M (2011): Central nervous system myelin: structure, synthesis and assembly. Trends in Cell Biology 21(10), 585-593.

Aggarwal S, Yurlova L, Snaidero N, Reetz C, Frey S, Zimmermann J, Pahler G, Janshoff A, Friedrichs J, Muller DJ, et al. (2011): A size barrier limits protein diffusion at the cell surface to generate lipid-rich myelin-membrane sheets. Dev Cell 21(3), 445-456.

Alberts B, Johnson A, Lewis J, Raff M, Roberts K, Walter P: Molecular biology of the cell.Garland Science Taylor \& Francis Group, 2002

Barres BA (2008): The Mystery and Magic of Glia: A Perspective on Their Roles in Health and Disease. Neuron 60(3), 430-440.

Baumann N und Pham-Dinh D (2001): Biology of Oligodendrocyte and Myelin in the Mammalian Central Nervous System. Physiological Reviews 81(2), 871-927.

Boggs J (2006): Myelin basic protein: a multifunctional protein. Cellular and Molecular Life Sciences 63(17), 1945-1961.

Bozzali M und Wrabetz L (2004): Axonal Signals and Oligodendrocyte Differentiation. Neurochemical Research 29(5), 979-988.

Brinkmann BG, Agarwal A, Sereda MW, Garratt AN, Müller T, Wende H, Stassart RM, Nawaz S, Humml C, Velanac V, et al. (2008): Neuregulin-1/ErbB Signaling Serves Distinct Functions in Myelination of the Peripheral and Central Nervous System. Neuron 59(4), 581-595.

Chang KJ, Susuki K, Dours-Zimmermann MT, Zimmermann DR, Rasband MN (2010): Oligodendrocyte myelin glycoprotein does not influence node of ranvier structure or assembly. $\mathrm{J}$ Neurosci 30(43), 14476-14481.

Chernoff GF (1981): Shiverer: an autosomal recessive mutant mouse with myelin deficiency. Journal of Heredity $\underline{72(2)}, 128$.

Chrast R, Saher G, Nave K-A, Verheijen MHG (2011): Lipid metabolism in myelinating glial cells: lessons from human inherited disorders and mouse models. Journal of Lipid Research $\underline{52(3)}$, 419-434.

Coetzee T, Fujita N, Dupree J, Shi R, Blight A, Suzuki K, Suzuki K, Popko B (1996): Myelination in the Absence of Galactocerebroside and Sulfatide: Normal Structure with Abnormal Function and Regional Instability. Cell 86(2), 209-219.

Colognato H und ffrench-Constant C (2004): Mechanisms of glial development. Current Opinion in Neurobiology 14(1), 37-44.

Deber CM und Reynolds SJ (1991): Central nervous system myelin: structure, function, and pathology. Clinical Biochemistry 24(2), 113-134.

Dyer CA und Benjamins JA (1989): Organization of oligodendroglial membrane sheets: II. Galactocerebroside:antibody interactions signal changes in cytoskeleton and myelin basic protein. J Neurosci Res 24(2), 212-221.

Fish KN (2001). Total Internal Reflection Fluorescence (TIRF) Microscopy. Current Protocols in Cytometry, John Wiley \& Sons, Inc.

Fitzner D, Schneider A, Kippert A, Möbius W, Willig K, Hell S, Bunt G, Gaus K, Simons M (2006): Melin basic protein-dependent plasma membrane reorganization in the formation of myelin. EMBO J 25(21), 5037-5048. 
Füllekrug J und Simons K (2004): Lipid Rafts and Apical Membrane Traffic. Annals of the New York Academy of Sciences 1014(1), 164-169.

Gaus K, Chklovskaia E, Fazekas de St. Groth B, Jessup W, Harder T (2005): Condensation of the plasma membrane at the site of T lymphocyte activation. The Journal of Cell Biology 171(1), 121-131.

Gaus K, Zech T, Harder T (2006): Visualizing membrane microdomains by Laurdan 2-photon microscopy (Review). Molecular Membrane Biology 23(1), 41-48.

Griffin JW und Thompson WJ (2008): Biology and pathology of nonmyelinating Schwann cells. Glia 56(14), 1518-1531.

Harauz G, Ishiyama N, Bates I (2000): Analogous standard motifs in myelin basic protein and in MARCKS. Molecular and Cellular Biochemistry 209(1), 155-163.

Harauz G, Ishiyama N, Hill CMD, Bates IR, Libich DS, Farès C (2004): Myelin basic protein-diverse conformational states of an intrinsically unstructured protein and its roles in myelin assembly and multiple sclerosis. Micron 35(7), 503-542.

Harauz G, Ladizhansky V, Boggs JM (2009): Structural Polymorphism and Multifunctionality of Myelin Basic Protein. Biochemistry 48(34), 8094-8104.

Harauz G und Libich DS (2009): The classic basic protein of myelin--conserved structural motifs and the dynamic molecular barcode involved in membrane adhesion and protein-protein interactions. Curr Protein Pept Sci 10(3), 196-215.

Hartline DK (2008): What is myelin? Neuron Glia Biology 4(02), 153-163.

Hu Y, Doudevski I, Wood D, Moscarello M, Husted C, Genain C, Zasadzinski JA, Israelachvili J (2004): Synergistic interactions of lipids and myelin basic protein. Proceedings of the National Academy of Sciences of the United States of America 101(37), 13466-13471.

Ishibashi T, Dakin KA, Stevens B, Lee PR, Kozlov SV, Stewart CL, Fields RD (2006): Astrocytes Promote Myelination in Response to Electrical Impulses. Neuron 49(6), 823-832.

Jacobson K, Mouritsen OG, Anderson RGW (2007): Lipid rafts: at a crossroad between cell biology and physics. Nat Cell Biol $\underline{9(1)}, 7-14$.

Jahn O, Tenzer S, Werner H (2009): Myelin Proteomics: Molecular Anatomy of an Insulating Sheath. Molecular Neurobiology 40(1), 55-72.

Kacem K, Lacombe P, Seylaz J, Bonvento G (1998): Structural organization of the perivascular astrocyte endfeet and their relationship with the endothelial glucose transporter: A confocal microscopy study. Glia 23(1), 1-10.

Kandel ER, Schwartz JH, Jessell TM: Principles of neural science.McGraw-Hill, Health Professions Division, New York 2000

Kessaris N, Fogarty M, lannarelli P, Grist M, Wegner M, Richardson WD (2006): Competing waves of oligodendrocytes in the forebrain and postnatal elimination of an embryonic lineage. Nat Neurosci 9(2), 173-179.

Kettenmann H, Hanisch U-K, Noda M, Verkhratsky A (2011): Physiology of Microglia. Physiological Reviews 91(2), 461-553.

Laux T, Fukami K, Thelen M, Golub T, Frey D, Caroni P (2000): Gap43, Marcks, and Cap23 Modulate $\mathrm{Pi}(4,5) \mathrm{p} 2$ at Plasmalemmal Rafts, and Regulate Cell Cortex Actin Dynamics through a Common Mechanism. The Journal of Cell Biology 149(7), 1455-1472.

Lingwood CA (2011): Glycosphingolipid Functions. Cold Spring Harbor Perspectives in Biology $\underline{3(7)}$.

Lubetzki C, Demerens C, Anglade P, Villarroya H, Frankfurter A, Lee VM, Zalc B (1993): Even in culture, oligodendrocytes myelinate solely axons. Proceedings of the National Academy of Sciences 90(14), 6820-6824. 
Michailov GV, Sereda MW, Brinkmann BG, Fischer TM, Haug B, Birchmeier C, Role L, Lai C, Schwab MH, Nave K-A (2004): Axonal Neuregulin-1 Regulates Myelin Sheath Thickness. Science 304(5671), 700-703.

Min Y, Kristiansen K, Boggs JM, Husted C, Zasadzinski JA, Israelachvili J (2009): Interaction forces and adhesion of supported myelin lipid bilayers modulated by myelin basic protein. Proceedings of the National Academy of Sciences 106(9), 3154-3159.

Nave KA und Trapp BD (2008). Axon-glial signaling and the glial support of axon function. Annual Review of Neuroscience. Palo Alto, Annual Reviews. 31: 535-561.

Nawaz S, Kippert A, Saab AS, Werner HB, Lang T, Nave K-A, Simons M (2009): Phosphatidylinositol 4,5-Bisphosphate-Dependent Interaction of Myelin Basic Protein with the Plasma Membrane in Oligodendroglial Cells and Its Rapid Perturbation by Elevated Calcium. The Journal of Neuroscience 29(15), 4794-4807.

Nedergaard M und Verkhratsky A (2012): Artifact versus reality-How astrocytes contribute to synaptic events. Glia $\underline{60(7)}, 1013-1023$.

Pereira JA, Lebrun-Julien F, Suter U (2012): Molecular mechanisms regulating myelination in the peripheral nervous system. Trends in Neurosciences 35(2), 123-134.

Perlmutter JD und Sachs JN (2011): Interleaflet Interaction and Asymmetry in Phase Separated Lipid Bilayers: Molecular Dynamics Simulations. Journal of the American Chemical Society 133(17), 65636577.

Piaton G, Gould RM, Lubetzki C (2010): Axon-oligodendrocyte interactions during developmental myelination, demyelination and repair. Journal of Neurochemistry 114(5), 1243-1260.

Pietraszewska-Bogiel A und Gadella TWJ (2011): FRET microscopy: from principle to routine technology in cell biology. Journal of Microscopy 241(2), 111-118.

Reits EAJ und Neefjes JJ (2001): From fixed to FRAP: measuring protein mobility and activity in living cells. Nat Cell Biol $\underline{3(6)}$, E145-E147.

Roach A, Takahashi N, Pravtcheva D, Ruddle F, Hood L (1985): Chromosomal mapping of mouse myelin basic protein gene and structure and transcription of the partially deleted gene in shiverer mutant mice. Cell 42(1), 149-155.

Schneider A, Länder H, Schulz G, Wolburg H, Nave K-A, Schulz JB, Simons M (2005): Palmitoylation is a sorting determinant for transport to the myelin membrane. Journal of Cell Science 118(11), 24152423.

Schroeder R, London E, Brown D (1994): Interactions between saturated acyl chains confer detergent resistance on lipids and glycosylphosphatidylinositol (GPI)-anchored proteins: GPI-anchored proteins in liposomes and cells show similar behavior. Proceedings of the National Academy of Sciences 91(25), 12130-12134.

Shaw AS (2006): Lipid rafts: now you see them, now you don't. Nat Immunol 7(11), 1139-1142.

Sherman DL und Brophy PJ (2005): Mechanisms of axon ensheathment and myelin growth. Nat Rev Neurosci 6(9), 683-690.

Simons K und Ikonen E (1997): Functional rafts in cell membranes. Nature $\underline{387(6633)}$, 569-572.

Simons K und Sampaio JL (2011): Membrane Organization and Lipid Rafts. Cold Spring Harbor Perspectives in Biology $\underline{3(10)}$.

Simons M, Krämer E-M, Thiele C, Stoffel W, Trotter J (2000): Assembly of Myelin by Association of Proteolipid Protein with Cholesterol- and Galactosylceramide-Rich Membrane Domains. The Journal of Cell Biology 151(1), 143-154. 
Stockmann-Juvala $\mathrm{H}$ und Savolainen K (2008): A review of the toxic effects and mechanisms of action of fumonisin B1. Human \& Experimental Toxicology 27(11), 799-809.

Taveggia C, Feltri ML, Wrabetz L (2010): Signals to promote myelin formation and repair. Nat Rev Neurol 6(5), 276-287.

Tong J, Nguyen L, Vidal A, Simon SA, Skene JHP, McIntosh TJ (2008): Role of GAP-43 in Sequestering Phosphatidylinositol 4,5-Bisphosphate to Raft Bilayers. Biophysical Journal $\underline{94(1)}$, 125133.

Trajkovic K, Dhaunchak AS, Goncalves JT, Wenzel D, Schneider A, Bunt G, Nave K-A, Simons M (2006): Neuron to glia signaling triggers myelin membrane exocytosis from endosomal storage sites. The Journal of Cell Biology 172(6), 937-948.

van Meer G (2011): Dynamic Transbilayer Lipid Asymmetry. Cold Spring Harbor Perspectives in Biology $\underline{3(5)}$.

van Meer G, Voelker DR, Feigenson GW (2008): Membrane lipids: where they are and how they behave. Nat Rev Mol Cell Biol 9(2), 112-124.

Viola A und Gupta N (2007): Tether and trap: regulation of membrane-raft dynamics by actin-binding proteins. Nat Rev Immunol 7(11), 889-896.

Willig KI, Kellner RR, Medda R, Hein B, Jakobs S, Hell SW (2006): Nanoscale resolution in GFPbased microscopy. Nat Meth $\underline{3(9)}, 721-723$. 


\section{Originalarbeit}

Diese Publikations-basierte Dissertation gründet sich auf die folgende Originalarbeit:

Fitzner D, Schneider A, Kippert A, Möbius W, Willig K, Hell S, Bunt G, Gaus K, Simons M (2006): Melin basic protein-dependent plasma membrane reorganization in the formation of myelin. EMBO J 25(21), 5037-5048.

http://dx.doi.org/10.1038/sj.emboj.7601376 